\title{
THE SPECTRUM OF COMET CUNNINGHAM, 1940c*
}

\author{
P. SWINGS, C. T. ELVEY, AND H. W. BABCOCK
}

\section{ABSTRACT}

Slit spectrograms of Comet Cunningham secured at the McDonald Observatory reveal well-resolved ultraviolet bands due to $O H$ and $N H$; only the lines of low rotational quantum number are observed, as in the case of $\mathrm{CH}$. The abundances of $O H$ and $N H$ molecules seem to be of the same order as that of $C N$. Each branch of the violet bands of $C N$ has two maxima, one corresponding to a rotational distribution for $T \simeq 400^{\circ} \mathrm{K}$ and one corresponding to $T \simeq 50^{\circ} \mathrm{K}$. The tail bands of $C N$ are absent. The authors discuss the variation with heliocentric distance of the relative intensities of the vibrational transitions. The rotational intensity distribution and the extension of the different bands in the head have been investigated. The cometary bands of $C H$ belonging to the two electronic transitions, $A^{2} \Delta \rightarrow x^{2} \Pi$ (near $\lambda 4300$ ) and $\mathrm{B}^{2} \Sigma^{-} \rightarrow \mathrm{x}^{2} \Pi$ (near $\lambda 3900$ ), are described. The bands observed between $\lambda 4000$ and $\lambda 4^{\mathrm{I}} 30$ are discussed but remain unidentified.

Twenty-four spectrograms of Comet Cunningham have been secured with the Cassegrain spectrograph of the McDonald Observatory between September 20, 1940, and January 6, I94I. In all cases the nucleus was kept on the center of the slit without trailing; only the spectrum of the head was considered. For the plates used in the present discussion the dispersions and the projected slit widths are given in Table I. The emul-

TABLE 1

OBSERVATIONAL MATERIAL

\begin{tabular}{|c|c|c|c|}
\hline $\begin{array}{l}\text { Wave-Length } \\
\text { Region }\end{array}$ & $\begin{array}{l}\text { Prisms and } \\
\text { Camera }\end{array}$ & $\begin{array}{l}\text { Dispersion } \\
\text { in } \mathrm{A} / \mathrm{mm}\end{array}$ & $\begin{array}{c}\text { Projected Slit } \\
\text { Width in } \\
\text { Angstroms }\end{array}$ \\
\hline $\begin{array}{l}3090 \ldots \ldots \ldots \\
3360 \ldots \ldots \ldots \\
3870 \ldots \ldots \ldots \\
4050 \ldots \ldots \ldots \\
4300 \ldots \ldots \ldots \ldots\end{array}$ & $\begin{array}{l}\text { quartz } f / \mathrm{I} \\
\text { quartz } f / \mathrm{I} \\
\text { glass } f / \mathrm{I} \\
\text { glass } f / \mathrm{I} \\
\text { glass } f / \mathrm{I}\end{array}$ & $\begin{array}{r}99 \\
\text { I37 } \\
89 \\
\text { I } 2 \\
\text { I } 45\end{array}$ & $\begin{array}{l}\text { I. } 34 \\
\text { I. } 86 \\
\text { I. } 2 \text { I } \\
\text { I. } 52 \\
\text { I. } 97\end{array}$ \\
\hline
\end{tabular}

sion used was Agfa Super-Pan Press, and the instrumental wave-length limit of our spectrograms was $\lambda 6420$. On most nights a spectrogram was taken of a star of solar type with the same instrument. This was intended to avoid confusion between emission features and spacings between solar absorption lines or bands. Such a difficulty arose only in the case of cometary features, such as the $C H$ lines, which are concentrated in, or are very near, the nucleus and appear in a region of strong solar background. It was much less pronounced in Comet Cunningham than in some yellowish comets scattering a larger amount of solar light compared to the molecular bands.

Our spectrograms reveal several new bands and some new features in known bands. It is the purpose of the present paper to discuss these new observations and their connection with the physical processes occurring in comets. The identification of new molecules in itself may help considerably in interpreting the essential physical cometary problems. It is well known that the primary process in the generation of cometary atmospheres is the liberation of occluded gases from the meteoric particles. ${ }^{\top}$ Subsequent photodissocia-

* Contributions from the McDonald Observatory, University of Texas, No. 38.

I The evaporation becomes important at small distances from the sun. 
tions of these primary gases will produce simpler molecules, some observed and some unobservable. In previous discussions of the primary molecules the absence of $\mathrm{NH}$ and $\mathrm{OH}$ has sometimes been emphasized, ${ }^{2}$ whereas the present paper will show that these two molecules are abundant.

The connection with interstellar molecules is also evident. The intensity distribution in cometary bands of heteronuclear molecules corresponds to a fairly low temperaturesay of the order of room temperature; the interstellar molecules show a distribution corresponding to about $2^{\circ}$ or $3^{\circ} \mathrm{K}$. The comets thus represent an intermediate step between the laboratory (or stellar) and the interstellar intensity distributions in bands, and the cometary observations may help in predicting or interpreting interstellar molecular lines.

All our observations, including those of the new bands of $O H$ and $N H$, agree with the hypothesis that the luminosity of the cometary gases is due to fluorescence excited by solar radiation.

\section{BANDS OF $O H$}

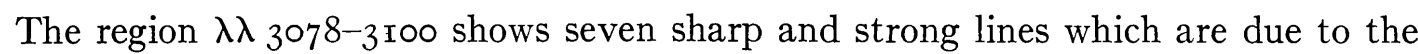
$(\circ, 0)$ transition of the ${ }^{2} \Sigma^{+} \rightarrow^{2} \Pi_{\text {inv }}$ system of $O H$. These lines are seen in Plate XIV, and their microphotograms on three different dates are given in Figure I. Besides those lines, several weak emissions appear between $\lambda_{3}{ }_{3} 34$ and $\lambda_{3} I_{5}$ and are presumably due to the (I, I) band; finally, two other extremely weak lines may be attributed to the $(2,2)$ transition. The wave lengths of these lines measured on three spectrograms and corrected for radial velocity are listed in Table 2 ; the laboratory wave lengths are taken from L. Grebe and O. Holtz ${ }^{3}$ (bands $\circ$, o and I, I) and from O. H. Dawson and H. L. Johnston 4 (band 2, 2). The observed lines of the $(0,0)$ transition are represented in Figure $2 .{ }^{5}$

The evidence for the (I, I) band of $O H$ is not quite conclusive, as the lines arising from the lowest rotational levels of the
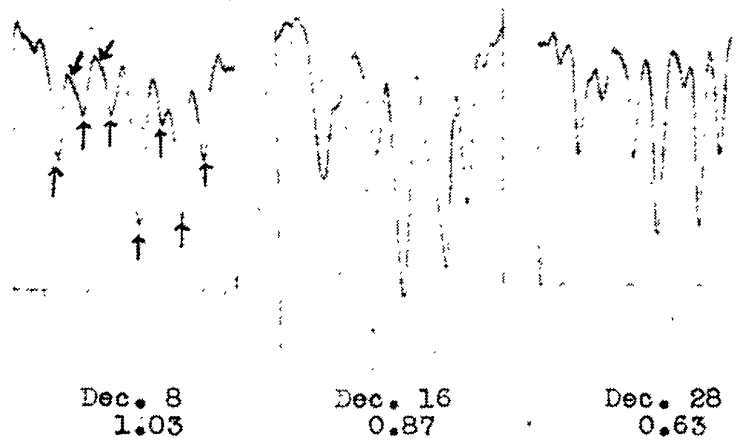

$00 c .28$
0.63

FrG. I.-Microphotometer tracings of the $\mathrm{OH}$ band in Comet Cunningham on December 8, I6, and 28, 1940. Emission lines are represented by downward deflections. $(\mathrm{o}, 0)$ Fortrat band of $C H\left(\mathrm{c}^{2} \Sigma^{+} \rightarrow \mathrm{x}^{2} \Pi\right)$ would appear in the same region. The two other electronic systems of $C H\left(\mathrm{~A}^{2} \Delta \rightarrow \mathrm{x}^{2} \Pi\right.$, near $\lambda 4300$, and $\mathrm{B}^{2} \Sigma^{-} \rightarrow \mathrm{x}^{2} \Pi$, near $\left.\lambda 3900\right)$ are observed in Comet Cunningham, so that the presence of $\mathrm{c}^{2} \Sigma^{+} \rightarrow \mathrm{x}^{2} \Pi$ would be plausible. The identifications indicated in Table $3,^{6}$ comprising both $(0,0)$ of $C H$ and $(\mathrm{I}, \mathrm{I})$ of $O H$, are thus probable for the region near $\lambda_{3 \mathrm{I} 40}$; the (I, I) band of $C H$ is absent.

The $R$ branches of the $O H$ bands are absent, except for the first lines $R_{2}\left(\frac{1}{2}\right)$ and $R_{2}\left(\mathrm{I} \frac{1}{2}\right)$ of the $(0,0)$ band at $\lambda 3084.03$ and $\lambda 3080.22$, which, as seen on the tracings of Figure $\mathrm{I}$, are probably present in the violet wing of $P_{\mathrm{r}}\left(2 \frac{1}{2}\right)$ at $\lambda 3086.3$ and of $P_{\mathrm{I}}\left(\mathrm{I} \frac{1}{2}\right)$ at $\lambda 308 \mathrm{I}$.6. According to Figure 2, the first line of the $R_{\mathrm{r}}$ branch has to come from the rotational level $J^{\prime}=2 \frac{1}{2}$, and then $P_{\mathrm{I}}\left(3 \frac{1}{2}\right)$ should be stronger, whereas the latter is absent. Similar-

${ }^{2} \mathrm{~K}$. Wurm, Zs.f. Ap., 8, 286, I934.

3 Ann.d. Phys., 39, г242, 1912; see also Heurlinger, Lund dissertation, I9r8.

${ }_{4}^{4}$ Phys. Rev., 43, 980, I933. $\quad 5$ According to W. Jevons, Report on Band Spectra, p. I64, I932.

${ }^{6}$ The data for $O H$ are from T. Hori, Zs.f. Phys., 59, 9I, I929, and from R. S. Richardson, A p.J., 77, I99, I933. 
ly, the first line of the $R_{2}$ branch should come from $J^{\prime}=I_{1} \frac{1}{2}$ and thus be weaker than $P_{2}\left(2 \frac{1}{2}\right)$; the next line $R_{2}\left(\mathrm{I} \frac{1}{2}\right)$ should be weaker than $P_{2}\left(3 \frac{1}{2}\right)$.

During the period in which our best ultraviolet spectrograms were taken (solar distance $r$ from $\mathrm{x} .03$ to 0.63 ), there has been no important change in the intensity distribution among the rotational lines. Our material does not permit a comparison of the relative intensities of the $(0,0),(\mathrm{I}, \mathrm{I})$, and $(2,2)$ bands of $O H$ because of the extreme faint. ness of $(\mathrm{I}, \mathrm{I})$ and $(2,2)$.

TABLE 2

$O H$ LINES $\left({ }^{2} \Sigma \rightarrow 2 \Pi\right)$ IN COMET CUNNINGHAM

\begin{tabular}{|c|c|c|c|c|c|}
\hline \multicolumn{2}{|c|}{ CoMEt } & \multicolumn{2}{|c|}{ LABORATORY } & & \multirow{2}{*}{ Notation* } \\
\hline Int. & $\lambda$ & Int. & $\lambda$ & & \\
\hline 2 & 3078.5 & Io & 3078.43 & & $\left(Q_{\mathrm{I}}\left(\mathrm{I} \frac{1}{2}\right)\right.$ \\
\hline I & 308 I. 6 & ro & 308 I. 64 & & $P_{\mathrm{I}}\left(\mathrm{I} \frac{1}{2}\right)$ \\
\hline 2 & $3086 \cdot 3$ & 8 & 3086.38 & & $P_{\mathrm{I}}\left(2 \frac{1}{2}\right)$ \\
\hline 4 & 3090.3 & $\begin{array}{l}\text { I0 } \\
\text { I } 2 \\
\text { I } 2\end{array}$ & $\left.\begin{array}{l}3090.46 \\
3089.84 \\
3089.84\end{array}\right\}$ & $(0,0)$ & $\begin{array}{l}Q_{2}\left(\frac{1}{2}\right) \\
Q_{2}\left(1 \frac{1}{2}\right) \\
Q_{2}\left(2 \frac{1}{2}\right)\end{array}$ \\
\hline I & $3093 \cdot 7$ & 4 & 3093.72 & & $P_{2}\left(\mathrm{I} \frac{1}{2}\right)$ \\
\hline 3 & 3096.4 & 5 & 3096.34 & & $P_{2}\left(2 \frac{1}{2}\right)$ \\
\hline 2 & $3099 \cdot 4$ & $\ldots \ldots$ & 3099.57 & & $P_{2}\left(3 \frac{1}{2}\right)$ \\
\hline$I-O$ & 3 I 34.5 & 3 . & $3 \mathrm{I} 34.55$ & & $Q_{\mathrm{I}}\left(\mathrm{I} \frac{1}{2}\right)$ \\
\hline I & $3 \mathrm{I} 37 \cdot \mathrm{I}$ & $\begin{array}{l}\text { I } \\
\text { I }\end{array}$ & $\begin{array}{l}3 \mathrm{I} 37.74 \\
3 \mathrm{I} 36 . \mathrm{x} 7\end{array}$ & & $\begin{array}{l}P_{\mathrm{I}}\left(\mathrm{I} \frac{1}{2}\right) \\
Q_{\mathrm{I}}\left(2 \frac{1}{2}\right)\end{array}$ \\
\hline$I-O$ & $3 \mathrm{I} 4 \mathrm{I} \cdot 5$ & 3 & $3 \mathrm{I} 4^{2} \cdot 49$ & (T) & $P_{\mathrm{I}}\left(2 \frac{1}{2}\right)$ \\
\hline I & $3 \mathrm{I} 47 \cdot 4$ & $\begin{array}{l}3 \\
I\end{array}$ & $\begin{array}{l}3147.44 \\
3146.58\end{array}$ & (-) & $\begin{array}{l}P_{1}\left(3 \frac{1}{2}\right) \\
Q_{2}\left(\mathrm{I} \frac{1}{2}\right)+Q_{2}\left(2 \frac{1}{2}\right)\end{array}$ \\
\hline$\circ$ & 3 I $49 \cdot 9$ & . & 3150.3 & & $P_{2}\left(\mathrm{I} \frac{1}{2}\right)$ \\
\hline$I-O$ & 3 I 52.4 & I & 3 I $5^{2} .95$ & & $P_{2}\left(2 \frac{1}{2}\right)$ \\
\hline $0-1$ & 3204 & $\ldots \ldots$ & 3203.94 & $(2,2)$ & $\left\{\begin{array}{l}P_{\mathrm{I}}\left(2 \frac{1}{2}\right) \\
\end{array}\right.$ \\
\hline $0-I$ & $32 \mathrm{II}$ & & $32 \mathrm{II}$ & & $P_{2}\left(\mathrm{I} \frac{1}{2}\right)$ \\
\hline
\end{tabular}

* See Fig. 2.

Figure 2 shows that if interstellar molecules of $\mathrm{OH}$ are abundant enough to be detected, the strongest line would be $Q_{\mathrm{I}}\left(\mathrm{I} \frac{1}{2}\right)$ at 3078.43 .

For instrumental, as well as theoretical reasons it is difficult to estimate the abundance of $O H$ molecules relative to $C N$ or to other constituents. The instrumental difficulty arises from the atmospheric absorption in this region and from the absorption by the UV-glass correcting-plate of the Schmidt camera. The theoretical difficulty lies in the uncertainty of the value of the oscillator strength. Oldenberg and Rieke ${ }^{7}$ have meas-

${ }^{7}$ J. Chem. Phys., 6, 439, I938. 


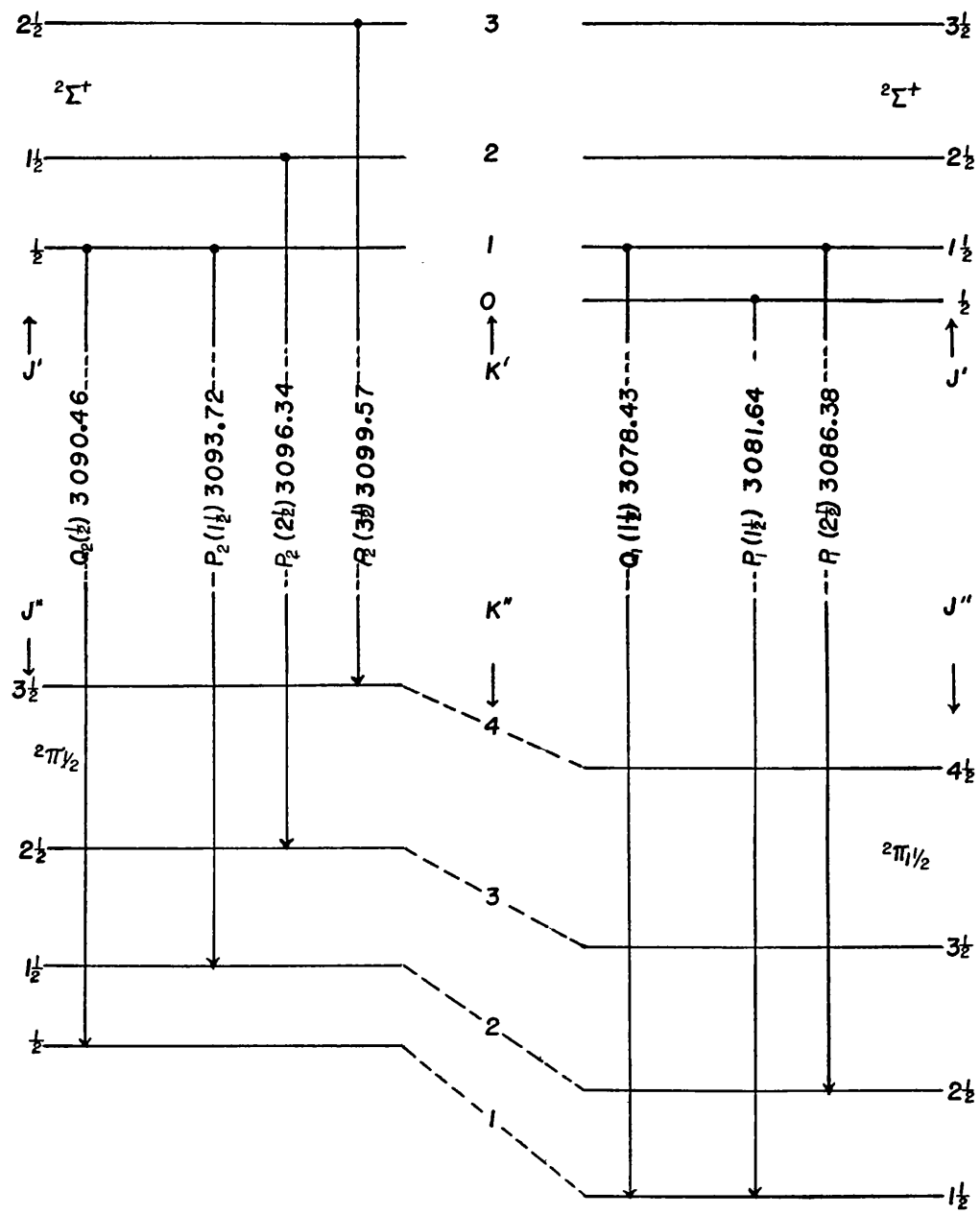

Frg. 2.-Diagram of the ${ }^{2} \Sigma^{+} \rightarrow{ }^{2} \Pi_{\text {inv }}$ band of $O H$ at $\lambda{ }_{306} \mathrm{~A}$. The small splitting of all the levels except $K^{\prime}=0$ has been omitted, since it is only observable in spectra taken with the highest resolvingpower. The lines observed in Comet Cunningham have been indicated.

TABLE 3

REGION $\lambda \lambda$ 3I34-3I53

\begin{tabular}{|c|c|c|c|c|c|}
\hline \multicolumn{2}{|c|}{ COMET } & \multicolumn{2}{|c|}{$(\mathrm{r}, \mathrm{I}) \mathrm{OH}$} & \multicolumn{2}{|c|}{$(0,0) C H$} \\
\hline Int. & $\lambda$ & $\lambda$ & Notation & $\lambda$ & Notation \\
\hline$I-0 \ldots$ & $3 I 34 \cdot 5$ & 3 I $34 \cdot 55$ & $Q_{\mathrm{I}}\left(\mathrm{I} \frac{1}{2}\right)$ & $\begin{array}{l}3135.6 \\
3136.2\end{array}$ & $\begin{array}{l}R_{2}(2) \\
R_{\mathrm{I}}(2)\end{array}$ \\
\hline I $\ldots \ldots$ & $3 I 37 \cdot I$ & $\begin{array}{l}3 \mathrm{I} 37.74 \\
3 \mathrm{I} 36 . \mathrm{I} 7\end{array}$ & $\begin{array}{l}P_{\mathrm{I}}\left(\mathrm{I} \frac{1}{2}\right) \\
Q_{\mathrm{I}}\left(2 \frac{1}{2}\right)\end{array}$ & $3 I 37 \cdot 4$ & $R_{2}(\mathrm{I})$ \\
\hline $\mathrm{I}-\mathrm{O} \ldots$ & $3 \mathrm{I} 4 \mathrm{I} \cdot 5$ & 3142.49 & $P_{I}\left(2 \frac{1}{2}\right)$ & $3142 \cdot 9$ & $Q_{2}(\mathrm{I})$ \\
\hline I. . & 3147.4 & $\begin{array}{l}3147.44 \\
3146.58\end{array}$ & $\begin{array}{l}P_{\mathrm{I}}\left(3 \frac{1}{2}\right) \\
Q_{2}\left(\mathrm{I} \frac{1}{2}, 2 \frac{1}{2}\right)\end{array}$ & $3147 \cdot 5$ & $P_{\mathrm{I}}(\mathrm{I})$ \\
\hline o.... & 3149.9 & 3 I 50.3 & $P_{2}\left(\mathrm{I} \frac{1}{2}\right)$ & $\begin{array}{l}3149.6 \\
3150.2\end{array}$ & $\begin{array}{l}P_{2}(2) \\
P_{I}(2)\end{array}$ \\
\hline $\mathbf{I}-0 \ldots$ & $3 \mathrm{I} 5^{2} \cdot 4$ & 3152.95 & $P_{2}\left(2 \frac{1}{2}\right)$ & 3152.9 & $P_{\mathrm{I}}(3)$ \\
\hline
\end{tabular}


ured the $f$ values for $O H$ to be of the order of $\mathrm{IO}^{-4}$ to $\mathrm{IO}^{-3}$. As was shown by $\mathrm{F}$. $\mathrm{E}$. Roach, ${ }^{8}$ the assumption of a similar low value for $C N, C H$, and $N H$ introduces a marked disagreement between the observed absorption intensities and those predicted from the sun's atomic constitution. R. S. Mulliken ${ }^{9}$ has reported preliminary calculations of $f$ values for diatomic molecules. According to him, the $C N$ bands are something like a hundred times more intense than the $O H$ bands.

Experimental confirmation of the small oscillator strength of $O H$ compared to $C N$ is given by laboratory measures. J. U. White ${ }^{9 a}$ finds that the $f$ value for $C N$ is $0.026 \pm .006$. T. Dunham, Jr. ${ }^{\text {I0 }}$ recently reported on his laboratory investigation of the $f$ values of $\mathrm{CH}$ and $\mathrm{CN}$, in collaboration with $\mathrm{R}$. B. King. There are many uncertainties involved in such experiments, such as the heats of dissociation and the vapor-pressure data; but their final values of $f$ are 0.06 for the $R_{2}$ (o) line of $C H$ and 0.075 for the $R(0)$ line of $C N$. These values are about one hundred times the $f$ values for $O H$, as measured by Oldenberg and Rieke.

On the whole, it seems safe to adopt $f$ values for $O H$ about one hundred times smaller than for $C N$ or $C H$. As the $O H$ emission is due to a fluorescence excitation similar to that of $C N$ or $C H$ and as the exciting solar radiation is also much weaker in the region of the $\mathrm{OH}$ bands than around the $\mathrm{CN}$ or $\mathrm{CH}$ bands, this means that, despite the faintness of the observed $O H$ lines, the abundance of $O H$ molecules must be comparable to that of $C N$, or even larger.

Incidentally, this low value of $f$ would make the detection of intersteller $O H$ molecules more difficult than that of $C N$, in the case of similar abundances; but the interstellar $O H$ molecules may very well be more abundant than those of $C N$.

A search was made for the bands of formaldehyde vapor $\mathrm{CH}_{2} \mathrm{O}$ whose electronic system appears in the region $\lambda<3600$ and has been investigated in the laboratory by $\mathrm{V}$. Henri and Schou ${ }^{\mathrm{II}}$ and by others; no trace is observed. A similar negative result was found by R. Wildt in Venus. ${ }^{12}$

\section{BANDS OF $N H$}

A group of seven strong, sharp lines observed near $\lambda 3360$ and appearing in the entire head may be attributed to the (o, o) and ( I, I) bands of the ${ }^{3} \Pi \rightarrow{ }^{3} \Sigma$ transition of $N H$. They are shown in Plate XIV $a$ and $b$, and the microphotometer tracings for four dates are given in Figure 3. The $(0,0)$ band has been analyzed very thoroughly in the laboratory, ${ }^{13}$ but the (I, I) transition is not yet well known. The measured wave lengths are listed in Table 4 .

The $\mathrm{OH}$ and $\mathrm{NH}$ bands whose fine structure appears so definitely on our spectrograms must be identical with the diffuse ${ }^{\mathrm{T} 4}$ bands observed by Lockyer in Comet Brooks (I9IIC) and by Van Biesbroeck and Henyey in Comet Encke;: ${ }^{\text {I5 }}$ but no identification was possible as long as the fine structure was not resolved. We may now add two new molecules, $\mathrm{NH}$ and $\mathrm{OH}$, to the five which were previously known with certainty in comets: $\mathrm{CN}, \mathrm{C}_{2}, \mathrm{CH}, \mathrm{N}_{2}^{+}$, and $\mathrm{CO}^{+}$. The observed bands of $\mathrm{NH}$ and $\mathrm{OH}$ are both resonance systems, just as for the other five molecules.

It is known that the Swan bands have an intensity distribution corresponding to a fairly high temperature (say approximately $3000^{\circ} \mathrm{K}$ ), and this is due to the fact that the $C_{2}$ molecule has no permanent electric dipole moment. On the contrary, $C H$ and $C N$,

${ }^{8} A$ p. J., 89, 99, I939.

9 Ap. J., 89, 287, 1939.

9a J. Chem. Phys., 8, 79, г940.

ro $P$ ub. A.A.S., ro, r23, г94r.

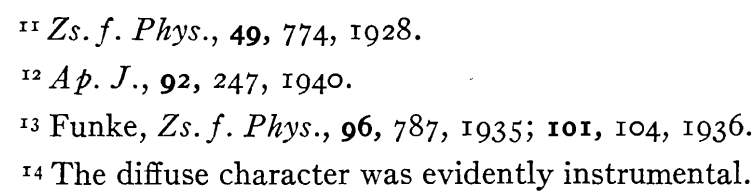

${ }^{15}$ Lockyer, Proc. R. Soc., A, 86, 258, r912; Van Biesbroeck and Henyey, Ap. J., 86, 622, 1937. R. C. Johnson had suggested (M.N., 87, 625, I927) that the bands observed by Lockyer in Comet Brooks belong to the second positive system of $\mathrm{N}_{2}$ (bands 0 , $\circ$ and I, 0 ). 
which have a permanent dipole moment, have a rotational intensity distribution of lowtemperature type. We now find such low-temperature distributions for the dipole molecules $O H$ and $N H$, which, like $C H$, give only a few well-separated lines. ${ }^{16}$

In the absence of any $f$ value for $N H$ it is difficult to obtain an idea regarding the abundance of $N H$ in cometary atmospheres; but it is probably of the same order of magnitude

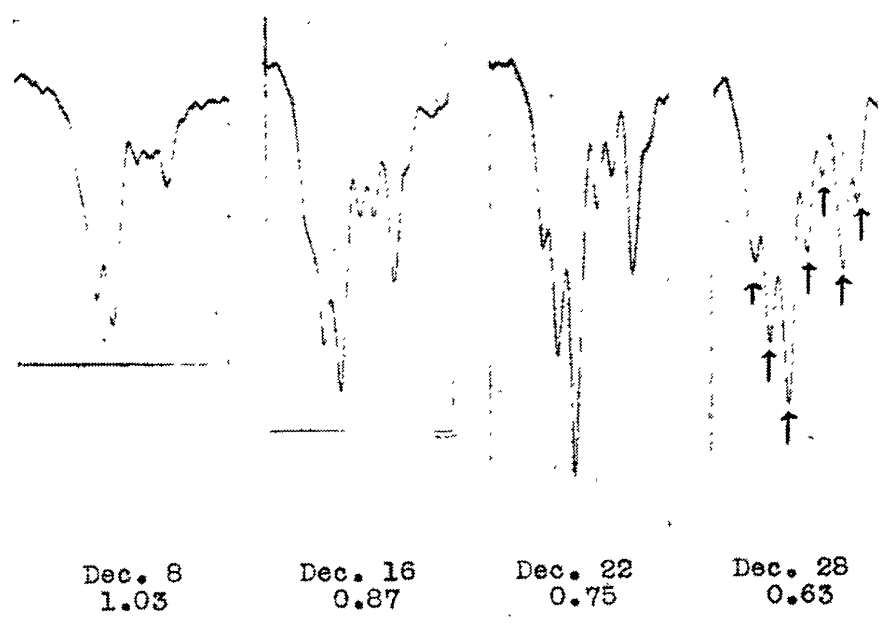

FIG. 3.-Microphotometer tracings of the $N H$ bands in Comet Cunningham on December 8, I6, 22, and 28, I940. Emissions are registered downward.

TABLE 4

$N H$ LINES IN COMET CUNNINGHAM $(3 \Pi \rightarrow 3 \Sigma)$

\begin{tabular}{|c|c|c|}
\hline Comet & $\begin{array}{l}\text { Labo- } \\
\text { ratory }\end{array}$ & Notation \\
\hline $3350.8(2) \ldots \ldots \ldots \ldots$ & 3350.8 & $R_{2}(\mathrm{I})$ \\
\hline $3354 \cdot I(4) \ldots \ldots \ldots \ldots$ & $\begin{array}{l}3353 \cdot 9^{2} \\
3353 \cdot 64\end{array}$ & $\begin{array}{l}R_{2}(\mathrm{O}) \\
R_{\mathrm{I}}(\mathrm{I})\end{array}$ \\
\hline $3357.9(8) \ldots \ldots \ldots \ldots$ & $\begin{array}{l}3357.83 \\
3357.8\end{array}$ & $\left.\begin{array}{l}R_{\mathrm{I}}(\mathrm{o}) \\
Q_{2}(2)\end{array}\right\}^{(0,0)}$ \\
\hline $336 \mathrm{I} \cdot 5(2) \ldots$ & $\begin{array}{l}3361 \cdot 73 \\
3361.0\end{array}$ & $\begin{array}{l}Q_{\mathrm{I}}(\mathrm{I}) \\
Q_{\mathrm{I}}(2)\end{array}$ \\
\hline $\left.\begin{array}{l}3364 \cdot 7(2) \\
3369 \cdot I(3) \\
3372.0(I)\end{array}\right\}$ & $\ldots \ldots \ldots$ & $(I, I)$ \\
\hline
\end{tabular}

as that of $C H$. Table 4 shows that if $N H$ molecules exist in interstellar space, which is very likely, their presence should be indicated by the line $\lambda 3357.83$.

Examination of Plate XIV $b$ and Figure 3 reveals changes in the intensity distribution of the $N H$ lines. For example, on December I6, I940 $(r=0.87)$, the lines $\lambda 336$ I.5 and $\lambda 3364.7$ were approximately of equal intensity, and they were stronger than $\lambda 3372.0$;

${ }^{16}$ The moments of inertia of $O H, N H$, and $C H$ are not very different but are much smaller than that of $C N$. Therefore, $\mathrm{OH}, \mathrm{NH}$, and $\mathrm{CH}$ show a few well-separated lines as compared to the many closely spaced lines of $C N$. 
whereas on December $28(r=0.63), \lambda 336 \mathrm{I} .5$ and $\lambda 3372.0$ were both stronger than $\lambda 3364.7$. Thus, a larger solar distance favors lower values of the rotational quantum number. This point will be discussed in detail for $C N$ in the following section.

\section{3. $C N$ BANDS}

Violet system.-Four sequences of the strong ${ }^{2} \Sigma^{+} \rightarrow{ }^{2} \Sigma^{+}$system have been observed, corresponding to $\Delta v=\mathrm{I}, \mathrm{O},-\mathrm{I}$, and $-2,{ }^{17}$ all of which have been observed previously, ${ }^{\mathrm{I}}{ }^{8}$ but the structure is better defined on our spectrograms
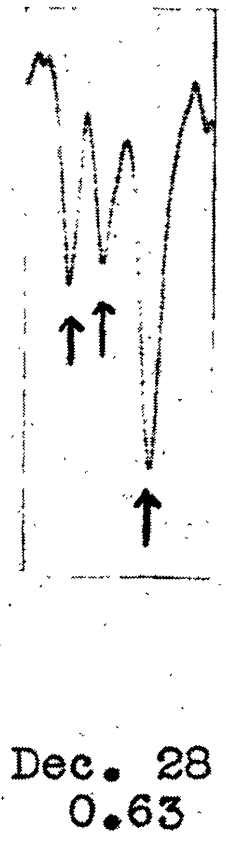

FIG. 4.-Microphotometer tracing of the $\Delta v=\mathrm{I}$ sequence of $C N$ on December 28, 1940. Emissions are registered downward. than in most previous descriptions. It has, therefore, seemed advisable to describe in detail the structures observed in Comet Cunningham. The $P$ branch is stronger than the $R$ branch; the general distribution of intensity

TABLE 5

$\Delta y=+\mathrm{r}$ SEQUENCE OF $C N$

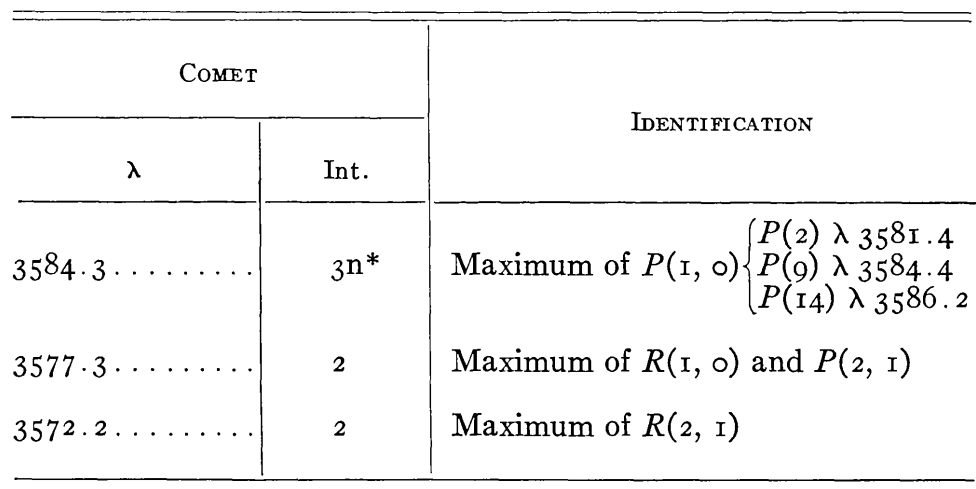

* Extending from $\lambda 3581.4$ to $\lambda 3586.3$.

among the vibrational transitions agrees satisfactorily with the Franck-Condon principle. ${ }^{19}$

Sequence $\Delta \mathrm{v}=\mathrm{I}$.- The analysis of these ultraviolet bands is more difficult than that of the other sequences because the heads are more closely spaced..$^{20}$ Similar to the laboratory intensities, the $\Delta v=+\mathrm{I}$ system is weaker than the $\Delta v=-$ I system (at $\lambda_{42} \mathrm{I} 6$ ). The sequence is shown in Plate XIV $a$ and $b$, and its microphotometer tracing in Figure 4 ; the wave lengths are listed in Table 5 .

The intensity of the third line, $\lambda 3572.2$, seems too high, compared to $\lambda_{3577.3}$; but this is probably due to the presence of a sharp intensity maximum near $\lambda 3572$ in the scattered solar spectrum.

Sequence $\Delta \mathrm{v}=$ o.- It appears from Plate XV that the relative intensities of its components vary with the distance to the sun; this is also shown in Figure 5, which gives the microphotometer tracings of some of the spectrograms. Hence, Table 6 , in which the measured wave lengths have been collected, does not represent the situation for all solar distances, but rather around the end of the series.

Summarizing, the $\Delta v=0$ sequence may be described as follows: Except for blending

${ }_{77}$ The old designations are: $C N \mathrm{v}, \mathrm{IV}$, III, II or $C y \mathrm{v}$, IV, III, II.

${ }^{18}$ See F. Baldet, thesis, Paris, I926.

${ }^{19}$ See Wurm, Zs.f.Ap., 5, 10, I932.

${ }^{20}$ The laboratory wave lengths of the heads are: $(\mathrm{r}, \mathrm{o}) \lambda 3590.42 ;(2, \mathrm{I}) 3585.9 \mathrm{I} ;(3,2) 3583.94$. We do not know of any previous observation of the structure of this sequence in comets. 
effects, the (o, o) and ( $\mathrm{I}, \mathrm{I})$ transitions are characterized by two maxima in each $P$ and $R$ branch, one corresponding to a distribution of $T \simeq 400^{\circ} \mathrm{K}$ and one corresponding to $T \simeq 50^{\circ} \mathrm{K}$; the behavior of the very weak $(2,2)$ transition is not so distinct.

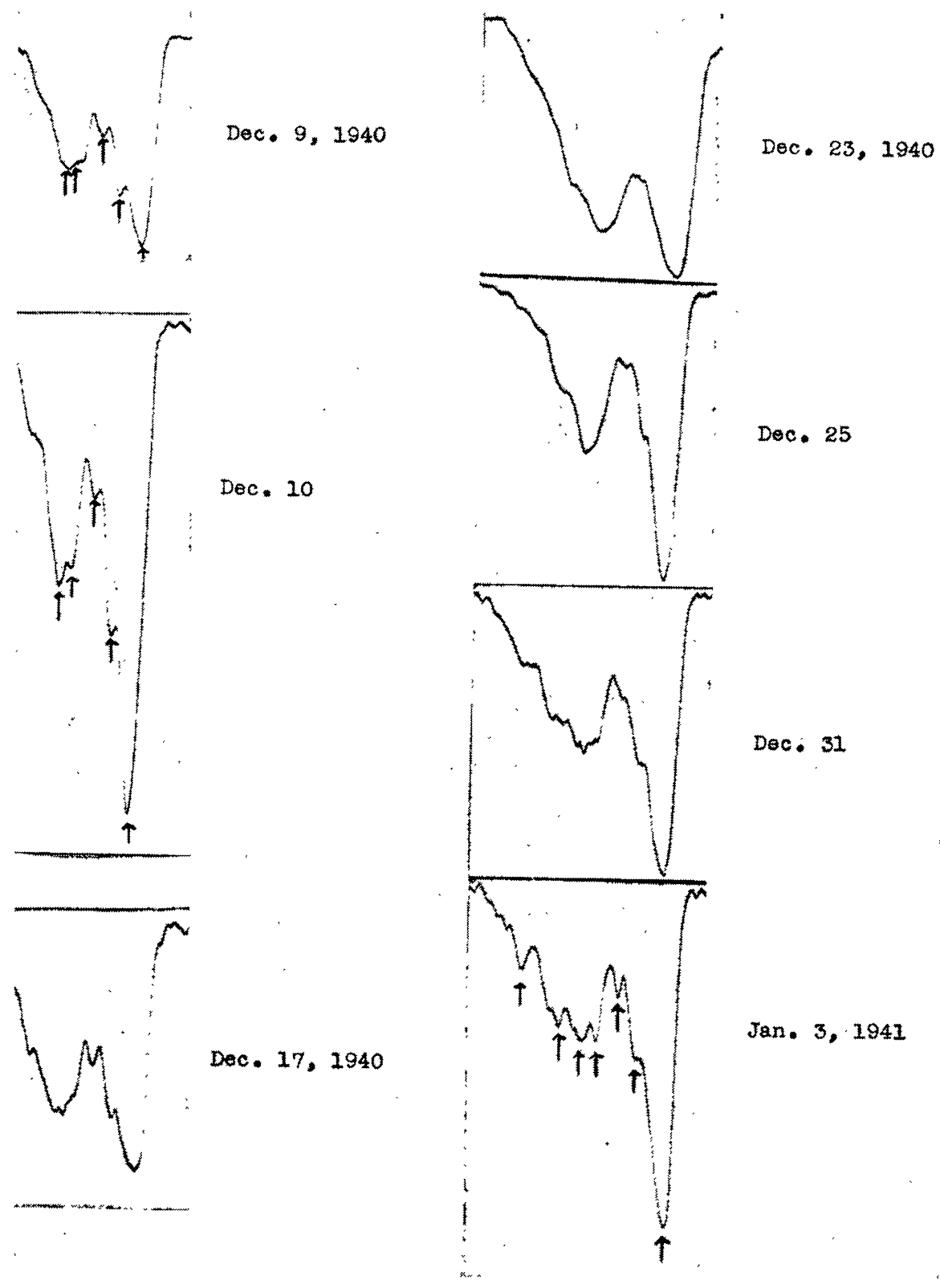

FIG. 5.-Microphotometer tracings of the $\Delta v=0$ sequence of $C N$ during the period December 9, I940, to January 3, I94I. Emissions are registered downward.

Several features seem to have escaped previous detection. The two sharper lines $\lambda_{3876.8}$ and $\lambda_{3873.5}$ have been observed previously. For example, they appear on the reproduction of Campbell's spectrograms of Comet Daniel; ${ }^{21}$ they were also observed by Wright in Comet Brooks; ;ra Dufay's observations ${ }^{22}$ will be discussed later on.

${ }^{21} A$ p. J., 28, 229, г908. $\quad$ 21a Lick Obs. Bull., 7, 8, I9г2. $\quad{ }^{22}$ C.R., 206, I949, I938. 
At first sight the observed structure reminds one somewhat of the structure of the $C N$ bands in active nitrogen; G. Herzberg ${ }^{23}$ found that, under these conditions, only a few rotational lines are strong, namely, those arising from $K^{\prime}=4,7$, I 5 and $v^{\prime}=0$, while all the other lines are extremely weak. But, as has been proved recently by $\mathrm{H}$. Beutler and Mark Fred, ${ }^{24}$ the behavior found by Herzberg is due to feeding by collisions from perturbing levels of the ${ }^{2} \Pi$ state of cyanogen. These collisions cannot be present in cometary atmospheres. The $K$ values of the strongest levels are also different, so that an analogy between the two behaviors has no sound basis.

TABLE 6

$\Delta v=\circ$ SEQUENCE OF $C N$

\begin{tabular}{|c|c|c|c|}
\hline \multicolumn{2}{|l|}{ Comet } & \multirow{2}{*}{ IDENTIFICATION } & \multirow{2}{*}{ Notes } \\
\hline$\lambda$ & Int. & & \\
\hline 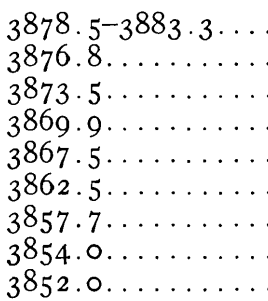 & $\begin{array}{l}20 \\
4 \mathrm{~S} \\
2 \mathrm{~S} \\
4 \\
4 \\
3 \\
3 \\
\mathrm{I} \\
0-\mathrm{I}\end{array}$ & $\begin{array}{l}P(0,0) \text { for } T \simeq 400^{\circ} \mathrm{K} \\
P(0, \circ) \text { for } T \simeq 50^{\circ} \mathrm{K} \\
R(0,0) \text { for } T \simeq 50^{\circ} \mathrm{K} \\
R(0,0) \text { for } T \simeq_{400^{\circ} \mathrm{K}} \\
P(\mathrm{I}, \mathrm{I}) \text { for } T \simeq_{400^{\circ} \mathrm{K}} \\
P(\mathrm{I}, \mathrm{I})+R(\mathrm{I}, \mathrm{I}) \text { for } l o w ~ T \\
R(\mathrm{I}, \mathrm{I})+P(2,2) \text { for } T \simeq_{400^{\circ} \mathrm{K}} \\
P(2,2) \text { for low } T \\
R(2,2) \text { for low } T\end{array}$ & $\begin{array}{l}I \\
2 \\
3 \\
4 \\
5 \\
6\end{array}$ \\
\hline
\end{tabular}

\section{NOTES TO TABLE 6}

I. On some spectrograms this broad band is double, with components at $\lambda 3880.2$ and $\lambda 3882.0$; the red edge is always sharp. In Comet Jurlof, McKellar recorded two maxima, at $\lambda_{3879.5}$ and $\lambda$ 388r.4. The appreciable intensity extension corresponds to the interval from $P(7)$ to the $P$ head. See also Bobrovnikoff, Pub. Lick Obs., I7, 434, I93I.

2. This line may be $10 \mathrm{~cm}^{-\mathrm{I}}$ wide and thus corresponds to $P(2,3,4)$ of $(0,0)$.

3. This line may be ro $\mathrm{cm}^{-1}$ wide and corresponds to $R(\mathrm{r}, 2,3)$ of $(o, \circ)$. The intensity ratio of $\lambda 3876.8$ and $\lambda 3873.5$ corresponds exactly to the relative intensities of the $P$ and $R$ branches.

4. $\lambda 3869.9$ is the maximum of a fairly broad feature on both sides of $R(7)$ of $(0,0)$. of $(\mathrm{I}, \mathrm{I})$.

5. $\lambda_{3} 867.5$ is the maximum of a rather broad feature around $P(9)$

6 . This line seems double on several plates; $P(2,2)$ may also influence the intensity distribution.

Sequence $\Delta \mathrm{v}=-\mathrm{I}$.- This sequence is shown in Plates XVI and XVII and in Figure 6. The measured wave lengths are listed in Table 7.

Sequence $\Delta \mathrm{v}=-2$. - Two very faint bands (intensity $\mathrm{I}-0$ ) have been observed at $\lambda_{4604}$ and $\lambda$ 4576; they are presumably the $P$ branches of $(0,2)$ and $(I, 3)$.

Tail bands. - These belong to the same system ${ }^{2} \Sigma^{+} \rightarrow^{2} \Sigma^{+}$as the other violet bands of $C N$, but arise from higher vibrational levels. ${ }^{25}$ Attempts have been made ${ }^{26}$ to identify the tail bands with the cometary features near $\lambda 4050$. Our material confirms Bobrovnikoff's conclusion ${ }^{27}$ that the tail bands strongest in the laboratory are not observed in com-

${ }^{23}$ Zs.f. Phys., 49, 512, 1928.

${ }^{24}$ Private communication.

${ }^{26}$ See, e.g., R. C. Johnson, $M . N .$, 87, 625, 1927.

${ }^{25}$ F. A. Jenkins, Phys. Rev., 3I, 539, I928.

${ }^{27}$ Lick Obs. Pub., r7, 44I, I93I. 
ets and that, when coincidences appear, they correspond only to very faint comet bands. It is thus quite certain that the tail bands are either absent or extremely weak.

Red system.-The electronic transition ${ }^{2} \Pi \rightarrow{ }^{2} \Sigma$ (often designated by $C N$ I or by $C y$ I) has several bands in the region covered by our spectrograms. The coincidences are listed in Table 8.

The information regarding the $C N$ red system in comets is still extremely unsatisfactory; our material is not very suitable for the investigation of this system, and Table 8 simply indicates that the ${ }^{2} \Pi \rightarrow{ }^{2} \Sigma$ system is very faintly present.

Variations in the relative intensities of the vibrational transitions.--Examination of Plate XVI shows that the intensity distribution among the bands of the $\Delta v=0$ sequence changed considerably

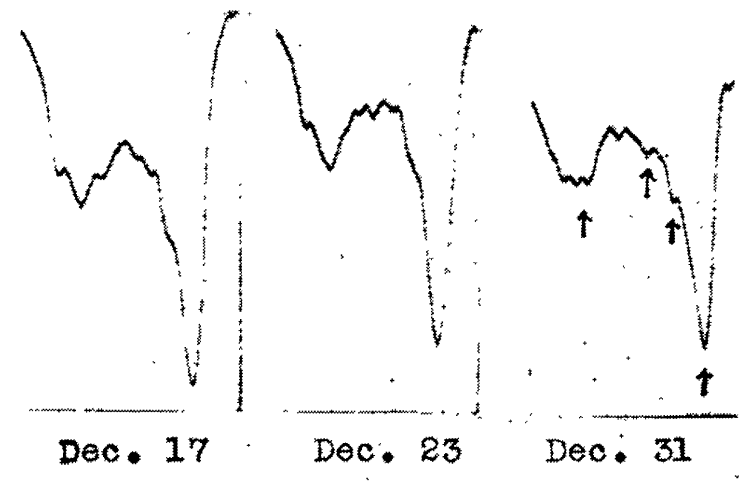

FIG. 6.-Microphotometer tracings of the $\Delta v=-$ I sequence of $C N$ on December I7, 23, and 3I, I940. Emissions are registered downward. between December 9, I940 ( $r=$ I.OI), and January 3, I94I $\left(r=0.5^{2}\right)$; this appears especially in the lines $\lambda_{3} 862.5$ and $\lambda_{3} 857.7$ and in the very weak lines of still shorter wave length. Whatever doubt there may remain

TABLE 7

$\Delta v=-\mathrm{I}$ SEQUENCE OF $C N$

\begin{tabular}{|c|c|c|c|}
\hline \multicolumn{2}{|l|}{ Сомet } & \multirow{2}{*}{ IDENTIFICATION } & \multirow{2}{*}{ Notes } \\
\hline$\lambda$ & Int. & & \\
\hline $\begin{array}{l}42 \mathrm{I} 4.7 \ldots \ldots \ldots \\
42 \mathrm{I} 0.2 \ldots \ldots \ldots \ldots \\
4206 \ldots \ldots \ldots \ldots \\
4 \mathrm{I} 97.0 \ldots \ldots \ldots \\
4 \mathrm{I} 93.0 \ldots \ldots \ldots \ldots \\
4 \mathrm{I} 84 \ldots \ldots \ldots \ldots \ldots \ldots \\
4 \mathrm{I} 80 \ldots \ldots \ldots \ldots \ldots \\
4 \mathrm{I} 64 \ldots \ldots \ldots \ldots \ldots\end{array}$ & $\begin{array}{c}6 \mathrm{n} \\
\mathrm{I} \\
\mathrm{O}-\mathrm{I} \\
2 \\
2 \\
\mathrm{I}-\mathrm{O} \\
\mathrm{I}-\mathrm{O} \\
0\end{array}$ & $\begin{array}{l}P(\mathrm{o}, \mathrm{I}) \text { for } T \simeq 400^{\circ} \mathrm{K} \\
P(\mathrm{o}, \mathrm{I}) \text { for } T \simeq 50^{\circ} \mathrm{K} \\
R(\mathrm{o}, \mathrm{I}) \text { for } T \simeq 50^{\circ} \mathrm{K} \\
R(\mathrm{o}, \mathrm{I}) \text { for } T \simeq 400^{\circ} \mathrm{K} \\
P(\mathrm{I}, 2) \text { for } T \simeq 400^{\circ} \mathrm{K} \\
R(\mathrm{I}, 2) \text { for } T \simeq 400^{\circ} \mathrm{K} \\
P(2,3) \text { for } T \simeq 400^{\circ} \mathrm{K} \\
R(2,3)+P(3,4)\end{array}$ & $\begin{array}{l}\text { I } \\
2 \\
2 \\
3 \\
3\end{array}$ \\
\hline
\end{tabular}

\section{NOTES TO TABLE 7}

I. The band extends from $\lambda 42$ I0.6 to $\lambda 42$ I 6.0 and has a sharp red edge; the limits correspond to $P(4)$ and $P(\mathrm{r} 8)$. sharp.

2. These lines appear only on the best exposures and are fairly

3. Fairly broad features.

as to the classification of these extreme parts of the observed complex pattern, there is, in any case, no doubt that they belong to the $(I, I)$ and $(2,2)$ transitions. The $(2,2)$ transition may be especially sensitive to a variation of solar excitation. The $(2,2)$ emission requires $C N$ molecules on the level $v^{\prime}=2$, and this must result from absorption in the $(2,0)$, $(2, \mathrm{I})$, or $(2,2)$ transitions. The $(2,0)$ transition at $\lambda 3360$ has an extremely small probability, as does the $(2, \mathrm{I})$ transition at $\lambda 3586$. Of course, $C N$ radicals may arrive at $v^{\prime \prime}=2$ after emission of (0.2) at $\lambda 4606$, but this band is extremely weak; or after emission of (I, 2) at $\lambda_{4} \mathrm{I} 97$, and this transition is of appreciable intensity. But again, emission of $(\mathrm{I}, 2)$ 
requires an appreciable population on $v^{\prime}=\mathrm{I}$, and the corresponding molecules must come mostly from $v^{\prime \prime}=1$. Thus, whatever the process followed in the excitation, most of the $(2,2)$ emission is due to molecules on $v^{\prime \prime}=2$ or $\mathrm{I}$, or, in other words, it is due to $C N$ molecules on excited vibrational levels. These populations are due essentially to solar excitation.

An intensity variation of the type shown in Plate XVI had been observed before, especially by F. Baldet, but under less favorable instrumental conditions.

Rotational intensity distribution in the $C N$ bands.-Many discussions have been published concerning this matter, especially since I937; and as our material supplies important new data on the subject, it has seemed worth while to summarize these recent discussions and to consider the present state of the question.

TABLE 8

RED System of $C N$ IN COMET CUNNINGHAM

\begin{tabular}{|c|c|c|c|c|c|c|c|c|}
\hline \multicolumn{2}{|l|}{ Comet } & \multicolumn{6}{|c|}{ LABORATORY } & \multirow[b]{2}{*}{ Notes } \\
\hline$\lambda$ & Int. & Transition & $\begin{array}{c}\lambda \\
\left(R_{2} \text { Head }\right)\end{array}$ & $\begin{array}{c}\lambda \\
\text { (Int. } \\
\text { Max.) }\end{array}$ & $\begin{array}{l}\text { Int. in } \\
\text { Flame }\end{array}$ & $\begin{array}{l}\text { Int. in } \\
\text { Vac. Tube }\end{array}$ & $\begin{array}{l}\text { Int. in Ac- } \\
\text { tive Ni- } \\
\text { trogen }\end{array}$ & \\
\hline $\begin{array}{l}4936 \ldots \ldots \ldots \\
5243 \ldots \ldots \ldots \\
5355 \ldots \ldots \ldots \\
5997 \ldots \ldots \ldots \ldots \\
6338 \ldots \ldots \ldots\end{array}$ & $\begin{array}{c}I-O \\
I-2 \\
I \\
3 \\
I\end{array}$ & $\begin{array}{l}(8,2) \\
(6, \mathrm{I}) \\
(7,2) \\
(7,3) \\
(4, \mathrm{I})\end{array}$ & $\begin{array}{l}4936 \\
5241 \\
5356 \\
5994 \\
6334\end{array}$ & $\begin{array}{l}4946 \\
525 I \\
5366 \\
6007 \\
6348\end{array}$ & $\begin{array}{r}\text { I } \\
2 \\
2 \\
2 \\
\text { IO }\end{array}$ & $\begin{array}{l}2 \\
3 \\
4 \\
6 \\
9\end{array}$ & $\begin{array}{l}3 \\
5 \\
6 \\
6 \\
6\end{array}$ & $\begin{array}{l}2 \\
3\end{array}$ \\
\hline
\end{tabular}

\section{NOTES TO TABLE 8}

I. Identification uncertain because of discordances in the intensities.

2. Partial contributor only.

3. Probably major contributor.

Wurm's original theory ${ }^{28}$ was that, owing to their permanent electric dipole, practically all the $C N$ molecules will be on the lowest rotational level, and their excitation by sunlight will thus proceed from that ground state. Thus the $C N$ emissions will degrade into clusters of a few lines each in the vicinity of the band origins. Adel ${ }^{29}$ showed that this is not strictly true in comets I9I $4 b$ (Zlatinsky) and I9I $5 a$ (Mellish). A clustering of lines appears around $P\left(\mathrm{I}_{3}\right)$ in Comet $\mathrm{I}_{9} \mathrm{I}_{4} b$ and around $P(8)$ in $\mathrm{I}_{9} \mathrm{I}_{5} a$; this showed that a fairly high rotational excitation is common in comet heads. Adel mentioned also ${ }^{30}$ that Minkowski's measures ${ }^{3 \mathrm{I}}$ of the spectrum of Comet I937 $f$ (Finsler) indicate two clusters of lines in the $(0,0)$ band, one at the $P$ head and one at the center of the band. Thus two types of distribution were observed: Adel's first suggestion was to accept Wurm's strict theory for the "origin cluster" and to assume an independent explanation for the "head cluster." For this Adel suggested that photodissociation of a parent-molecule-for example, $C_{2} N_{2}$ - may have provided the $C N$ radical with residual rotational (and possibly vibrational) energy.

Wurm ${ }^{32}$ then tried to complete his initial hypothesis by considering the effects upon the rotational distribution of the absorptions of solar light and of the subsequent emissions. He showed that, owing to the differences in intensity of the $R$ and $P$ transitions in

\footnotetext{
${ }^{28}$ Handb. d. Ap., 7, 307, 1936.

${ }^{29}$ Pub. A.S.P., 49, 254, I937.

$3^{\circ}$ Ibid., p. 348 .

${ }^{3 x}$ Pub. A.S.P., 49, 276, I937.

${ }^{32} Z s . f . A p .$, I5, II 5, I938. See also $A p . J ., 89,3$ I2, I939.
} 
emission and absorption of the ${ }^{2} \Sigma \rightleftarrows^{2} \Sigma$ type, higher rotational quantum numbers may be reached, as long as the frequency of the absorption processes in the photographic region is higher than $\mathrm{I} / \tau_{r}, \tau_{r}$ being the lifetime of the rotational levels. Thus, owing to the great intensity of solar radiation, the $C N$ molecules become and remain excited at high rotational levels. In a band system with $Q$ branches the process is slowed down, since the $Q$ branch is generally the strongest. The distribution of intensity among the rotational lines varies with the heliocentric distance, and this effect depends upon the frequency at which fluorescence occurs.

According to this revised theory, Wurm would thus dispose of the "origin clusters" altogether and would produce the "head clusters" by fluorescence. But Adel ${ }^{33}$ pointed out that the "origin clusters" do exist; thus, if fluorescence, rather than dissociation, is the mechanism governing the formation of the "head clusters," some other process must explain the "origin clusters."

P. Swings and M. Nicolet ${ }^{34}$ gave an alternative interpretation of the intensity distribution in the $C N$ and $C H$ bands. Taking into account the theoretical intensity factors and the resolving-power of the instruments, Swings and Nicolet found that the observed distributions in the $C H$ bands and in the $C N$ " head clusters" agree well with a Boltzmann rotational distribution at a temperature of the order of $300 r^{-\frac{1}{2}}$ degrees absolute. They suggested that the distribution on the rotational levels may be primarily due to the far infrared radiation of the meteoric matter, which, by application of Stefan's law, assumes a temperature of about $300 r^{-\frac{1}{2}}$. This suggestion was criticized by Wurm, ${ }^{35}$ who pointed out that, owing to the dilution of the nuclear radiation, the final distribution for the majority of the molecules would still correspond to a very low temperature ( $5 a y 5^{\circ}-\mathrm{I} 5^{\circ} \mathrm{K}$ ). This objection, which is applicable to $C N$, does not seem as plausible for $C H$, whose lines are concentrated near the nucleus.

In any case, if the suggestion of Swings and Nicolet is correct for $C N$, we should expect a different rotational intensity distribution at different distances from the nucleus. Our material is suitable for this discussion. Although it is difficult to settle the question, owing to the large variations in absolute intensities, it seems rather certain that the two sharp lines $\lambda_{3} 876.8$ and $\lambda 3873.5$ have exactly the same intensity distribution as the "high-temperature" lines with respect to the distance from the nucleus. This speaks against the hypothesis put forward by Swings and Nicolet. On the other hand, the practical side remains that the intensity distribution closely simulates that of a Boltzmann distribution at a temperature of the order of $100^{\circ}-400^{\circ} \mathrm{K}$. This shows definitely that, whatever the origin of the rotational distribution, it must be of the Boltzmann type, or nearly so. Wurm's fluorescence process may be most essential, but one might also consider that the rotational distribution was acquired near the nucleus and then maintained (or even enriched) by absorption of solar light.

Extending Adel's observation of a different rotational structure in two comets at different distances to the sun, J. Dufay ${ }^{36}$ examined the values of the quantum number $K$ corresponding to the maximum of intensity in the $P$ and $R$ branches for various comets observed at different heliocentric distances $r$. He finds a regular trend from $K=6$ at $r=\mathrm{I} .8$ to $K=\mathrm{I} 4$ at $r=0.5$. Dufay observed also on his objective-prism spectrograms three weak lines near $P(2)\left(\lambda_{3876.5}\right), R(\mathrm{I})\left(\lambda_{3874.3)}\right.$, and $R(2)\left(\lambda_{3873.0)}\right.$ of the (o, o) band and similar lines for the (I, I) transition. But, contrary to what we observe, he finds the $R$ lines to be stronger than $P(2)$ and to subsist alone on weak plates. This is quite strange, as the $P$ branch is always stronger than the $R$ branch. Dufay tries to explain the presence of molecules on the levels of very low rotation by Wurm's fluorescence process, assuming, for example, that certain molecules may have lost their rotational

33 Pub. A.S.P., 50, 247, I938. Referring to the two lines measured by R. Minkowski at $\lambda_{3} 874$ and

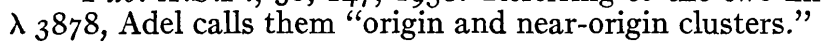

$$
{ }^{34} A \text { p. J., 88, I73, I938. } \quad 35 A \text { p. J., 89, 31 2, I939. } \quad{ }^{36} \text { Op. cit., p. 1948. }
$$


energy between two successive absorptions. It seems to us that any effect involving only Wurm's fluorescence mechanism will not be capable of explaining a first, very sharp maximum around $K^{\prime}=3$ or 4 and then a second, broad maximum around $K^{\prime}=8$. A fluorescence effect would rather give a continuous distribution.

McKellar ${ }^{37}$ examined the $C N$ structure on a plate of high spectral purity (projected slit width at $\lambda 3880$ only $0.6 \mathrm{~A}$ ) of Comet r 939 (Jurlof, Achmarof, Hassel). The $P$ branch shows two maxima of intensity at $\lambda_{388}{ }^{8} .4\left(K^{\prime}=I_{3}\right.$ and $\lambda_{3879.5}\left(K^{\prime}=8\right)$. McKellar states that the intensity of such a band cannot be represented by any function based on thermal equilibrium. Pending more detailed information, McKellar's statement does not seem quite convincing. A thermal equilibrium distribution may give rise to two maxima because of the combined effect of the individual line intensities and of the different spacings between these lines..$^{8}$ On some of our spectrograms the broad $P(0,0)$ branch appears also double with maxima at $\lambda_{3880.2}$ and $\lambda_{3} 882.0$, but this behavior may possibly be explained by an equilibrium distribution. McKellar suggests that the $C N$ emission takes place by the photodissociation of perhaps more than one type of molecule containing the $C N$ radical, each type of dissociation giving to $C N$ a characteristic amount of rotational energy. He also draws the radical consequence that "differences in the structure of the $C N$ bands like that examined recently by Adel for Comets I9I $4 b$ and I9I $5 a$ would be attributable to differences in gaseous constitution of the cometary head."

This hypothesis is contradicted by Dufay's observation of a continuous increase of $K_{\max }$ with decreasing $r$. We have also compared several spectrograms corresponding to values of $r$ from I.OI to $0.5^{2}$ and have measured the distance between the sharp edge of broad $P(\mathrm{o}, \mathrm{o})$ and the sharp line $\lambda_{3} 876.8$ ( $P$ branch at low temperature). This distance is found to vary practically continuously from $5.7 \mathrm{~A}$ at $r=1.01$ to $6.6 \mathrm{~A}$ at $r=0.5^{2}$, indicating an increase in $K_{\max }$ for smaller $r$. It is true that the shift in the band maximum of comet I9I4 $b(r \simeq 0.7)$ compared to I9I $5 a(r \simeq$ I.2) seems a little larger than in Comet Cunningham for values of $r$ from I.OI to $0.5^{2}$. However, considering the difficulty of such measurements, it seems rather certain that we have to deal with a unique phenomenon and that the distribution on the $K$ 's really varies with the solar distance. Actually our observation agrees with the variation of theoretical profile ${ }^{39}$ corresponding to $T \simeq 300 r^{-\frac{1}{2}}$.

In any case, the interpretation of the essential features in Table 6 seems unequivocal, and we have to assume that two types of $C N$ radicals exist in the comet with completely different rotational distribution: one corresponds to about $T \simeq 300 r^{-\frac{1}{2}}$, and the other corresponds to $T \simeq 50^{\circ} \mathrm{K}$. That these two types may coexist results from the very low densities in comet heads. Zanstra's and Wurm's investigations have shown clearly that the number of molecules per cubic centimeter is of the order of one, so that collisional effects are unimportant. Actually, the free path of the particles is of the same order as the diameter of the head, or even larger. Wurm's fluorescence process is unable to interpret these two types; and it seems more likely, as has been suggested already by others, that there are two types of parent-molecules or that one type of parent-molecule may be photodissociated in two ways. In each case the $C N$ molecules would leave the parent-substance with a certain rotational (and possibly vibrational) distribution, which may be then either maintained or not maintained by absorption of solar radiation.

Extension of different bands in the head.-Plates XIV and XVII show that $O H$ is concentrated near the nucleus, like $\mathrm{CH}$; $\mathrm{NH}$ extends farther, about in the same way as $C N$, although the intensity gradient of $N H$ may be larger than that of $C N$. It also appears that $C_{2}$ extends all over the head, whereas the group of lines near $\lambda 4050$ is concentrated near the nucleus, like $\mathrm{CH}$ and $\mathrm{OH}$. All the observed molecules result from the photodissociation of more complex occluded gases. In order to obtain $\mathrm{CH}, \mathrm{CN}, \mathrm{C}_{2}, \mathrm{NH}, \mathrm{OH}, \mathrm{N}_{2}^{+}$, and $\mathrm{CO}^{+}$by photodissociations and ionizations it is necessary to assume several parent-

${ }^{37}$ Pub. A.S.P., 52, 283, 1940. $\quad{ }^{38}$ Swings and Nicolet, op. cit.

${ }^{39} A$ p. J., 88, I73, 1938, Fig. 2. 
molecules. Considered by Wurm and others are dicyanogen $\mathrm{C}_{2} \mathrm{~N}_{2}$ and acetylene $\mathrm{HC}-\mathrm{CH}$; these particles may themselves result from the dissociation of still more complex, grandparent molecules liberated from their occluded state in the solid meteoric nucleus. ${ }^{40}$

The parent-molecules which were occluded in the meteoric nucleus are freed by the heating of the solid matter. They leave with velocities corresponding to their thermal motions. Once they become dissociated by solar radiation, the corresponding elementary particles may acquire higher velocities in the process of photodissociation..$^{\mathrm{II}}$ The path traveled by an elementary particle in the head corresponds to the provided initial velocity multiplied by the interval spent by the molecule in the field of solar radiation before being photodissociated or photo-ionized.

Considering the various extensions of different molecules, we may exclude the possibility that the head itself contains a considerable amount of dust particles from which occluded gases are liberated and then photodissociated. This is very unlikely, as it would not explain why certain types of molecules are liberated near the nucleus, whereas others appear in the entire head. We are thus left with two hypotheses.

r. The parent-molecules extend appreciably into the head, ${ }^{42}$ having moved away from the nucleus either by their own thermal velocities or, more likely, by the residual kinetic energy resulting from a photodissociation of a grandparent particle. In this hypothesis it is obvious that the observed rotational intensity distribution must be the same at different distances from the nucleus if the rotational energies of the diatomic radicals result from the photodissociation process.' The resulting picture is rather complex, as it involves the velocity of the parent-molecules and their a verage lifetime in the solar radiation field combined with the analogous characteristics of the diatomic radicals.

2. The parent-molecules are photodissociated in the neighborhood of the meteoric nucleus; thus, the observed extensions correspond really to the path of the diatomic molecules. These are formed with a certain rotational energy. They would lose this energy very soon by emission of the infrared pure rotational spectrum ${ }^{43}$ in the absence of radiative absorption processes. We should then find all the molecules on practically one rotational level at large distances from the nucleus; this is not confirmed by the observations. Actually, if the interval beween two absorptions of solar radiation is smaller than the average life of molecules on their rotational levels, they may keep their rotational distribution or modify it in one way or another; for example, they may favor the higher rotational states according to Wurm's mechanism.

Let us go into the details of the case of $C N$. An undetermined parent-molecule dissociates and produces the $C N$ radicals near the meteoric nucleus. ${ }^{44}$ Even if the photodissociation does not provide a rotational excitation to $C N$, these molecules may, in the close neighborhood of the nucleus, assume a rotational distribution corresponding approximately to $T \simeq 300 r^{-\frac{1}{2}}$. These molecules will move away from the nucleus, but the rotational levels will remain fed-gaining a little or losing a little-by absorption processes. We shall observe in the whole head a distribution corresponding to a temperature of the order of $300 r^{-\frac{1}{2}}$; it may be somewhat higher if Wurm's favoring mechanism is predominant or somewhat lower if the absorption processes are not frequent enough.

As for the "low-temperature distribution" observed for $C N$, it is presumably due to

${ }^{40}$ G. P. Merrill (Proc. Amer. Phil. Soc., 65, I I9, I926) found $\mathrm{CO}$ and $\mathrm{CO}_{2}$ occluded in meteorites; hence $\mathrm{CO}^{+}$presumably results from one of them. It is interesting to note that $\mathrm{CH}_{4}$ was also found. $\mathrm{OH}$ results probably from the photodissociation of water vapor.

4I Wurm, $A$ p. J., 89, 3 I 2, I939.

${ }^{42}$ Adel, Pub. A.S.P., 49, 254, I937.

43 In the case of $C_{2}$ this spectrum is forbidden; a lower density of radiation is sufficient to "feed" the rotational levels of $C_{2}$.

44 Or under conditions liberating a rotational energy distribution corresponding to about $T \simeq 300 r^{-\frac{1}{2}}$. 
the photodissociation of a parent-molecule 45 under conditions leaving little rotational energy to $C N$, as at larger distances from the nucleus.

It is not quite clear why the two types of $C N$ molecules extend exactly to the same distance from the nucleus. Their lifetimes are evidently the same. Therefore the observed extensions require that the initial velocities provided by thermal motion and photodissociation are identical.

\section{TABLE 9}

$(\circ, 0)$ BAND OF $\mathrm{B}^{2} \Sigma^{-} \rightarrow \mathrm{x}^{2} \Pi$ OF $C H$

\begin{tabular}{|c|c|c|c|c|}
\hline \multicolumn{2}{|c|}{ Сомeт } & \multirow{2}{*}{$\frac{\text { LABORATORY }}{\lambda}$} & \multicolumn{2}{|c|}{ Designation } \\
\hline$\lambda$ & Int. & & Branch & $\mathrm{K}^{*}$ \\
\hline 3886.6 & o & 3886.4 & $Q_{2}$ & I \\
\hline 3890.0 & $\mathrm{I}-2 \mathrm{n}$ & $\begin{array}{l}3889 \cdot I \\
3889 \cdot 8 \\
3888 \cdot 9 \\
389 \text { I. } 2 \\
3890 \cdot 5 \\
3891 . \mathrm{I} \\
3890 \cdot \mathrm{I}\end{array}$ & $\begin{array}{c}Q_{\mathrm{I}} \\
Q_{\mathrm{I}} \\
Q_{2} \\
Q_{\mathrm{I}} \\
Q_{2} \\
P_{2} \\
{ }^{P} Q_{\mathrm{I} 2}\end{array}$ & $\begin{array}{l}\text { I } \\
2 \\
2 \\
3 \\
3 \\
\text { I } \\
\text { I }\end{array}$ \\
\hline $3893 \cdot I$ & I & $3892 \cdot 9$ & $P_{\mathrm{I}}$ & I \\
\hline $3897 \cdot 2$ & $I-2$ & $\begin{array}{l}3897 \cdot 5 \\
3896.5\end{array}$ & $\begin{array}{l}P_{\mathrm{I}} \\
P_{2}\end{array}$ & $\begin{array}{l}2 \\
2\end{array}$ \\
\hline 3902.6 & $\mathrm{I}-2$ & $\begin{array}{l}3902.6 \\
3902.0\end{array}$ & $\begin{array}{l}P_{\mathrm{I}} \\
P_{2}\end{array}$ & $\begin{array}{l}3 \\
3\end{array}$ \\
\hline $3908 \cdot 3$ & $I-2$ & $\begin{array}{l}3908 \cdot 3 \\
3907.8\end{array}$ & $\begin{array}{l}P_{I} \\
P_{2}\end{array}$ & $\begin{array}{l}4 \\
4\end{array}$ \\
\hline $39 I 4 \cdot 5$ & I & $\begin{array}{l}39 \text { I } 4.4 \\
39 \text { I } 4.0\end{array}$ & $\begin{array}{l}P_{\mathrm{I}} \\
P_{2}\end{array}$ & $\begin{array}{l}5 \\
5\end{array}$ \\
\hline $392 \mathrm{I} \cdot 5$ & $I-0$ & $\begin{array}{l}392 \text { I.I } \\
3920.7\end{array}$ & $\begin{array}{l}P_{\mathrm{I}} \\
P_{2}\end{array}$ & $\begin{array}{l}6 \\
6\end{array}$ \\
\hline
\end{tabular}

The different extension of two molecules in the head results from the characteristics of the mechanism which liberated them and from the individual electronic states leading to dissociation or ionization. These factors are not yet well enough known to permit a detailed comparison.

\section{BANDS OF $C H$}

The presence of $C H$ lines of low rotational quantum number has been suspected for many years $4^{4}$ and has been fully accepted since $M$. Nicolet 47 demonstrated the excellent agreement between the cometary wave lengths and the very first $Q, R$, and $P$ lines of the

${ }_{45}$ This may mean another photodissociation process of the same parent-molecule or the photodissociation of another parent. Dust may exist at a great distance from the nucleus and may also liberate or evaporate some parent-molecules.

${ }_{46}$ Bobrovnikoff, op. cit., p. 443 .

${ }^{47}$ Zs.f. Ap., 15, г54; 1938. 
$\mathrm{A}^{2} \Delta \rightarrow \mathrm{x}^{2} \Pi$ spectrum of $C H$. Further evidence in favor of this identification was added by J. Dufay, ${ }^{48}$ who also identified the $\mathrm{B}^{2} \Sigma \rightarrow \mathrm{x}^{2} \Pi$ band near $\lambda$ 3900. As Dufay's work was based exclusively on objective-prism material and because of the recent laboratory reinvestigation of the whole $C H$ spectrum by E. Fagerholm, ${ }^{49}$ it seemed desirable to reexamine the $\mathrm{CH}$ problem on the basis of our slit spectrograms.

Comet Cunningham is especially suitable for a discussion of molecular emission, owing to the general faintness of the diffused solar spectrum. But since $C H$ is concentrated near the nucleus, there is no escape from blending with the Fraunhofer spectrum; consequently, great care has to be exercised in the attribution of observed intensity maxima to a molecular emission; our cometary spectra were always compared to solar spectra taken under similar conditions. Fagerholm's molecular notations have been used throughout in this section. The $\mathrm{c}^{2} \Sigma^{+} \rightarrow \mathrm{x}^{2} \Pi$ system near $\lambda_{3 \mathrm{I}} 45$ (exc. pot. of $\mathrm{c}^{2} \Sigma^{+}=3.93 \mathrm{v}$.) has

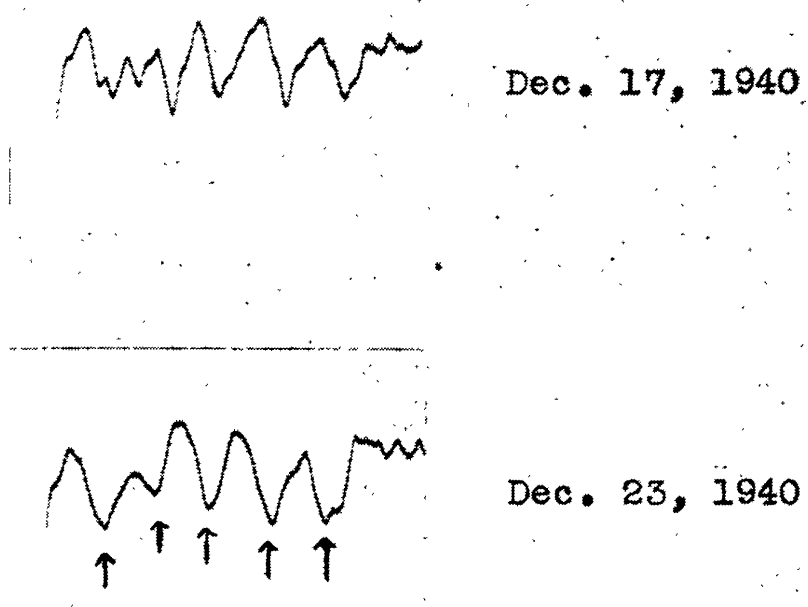

FIG. 7.-Microphotometer tracings of the $\mathrm{B}^{2} \Sigma^{-} \rightarrow \mathrm{x}^{2} \Pi$ band of $C H$ on December $\mathrm{I} 7$ and 23 , I940. Emissions are registered downward.

been considered in section $\mathrm{I}$, where it was shown that it is impossible to separate it from the ( $\mathrm{I}, \mathrm{I})$ band of $O H$, with the help of our material.

System $\mathrm{B}^{2} \Sigma^{-} \rightarrow \mathrm{x}^{2} \Pi$.- - Laboratory data are available for the following bands: (o, o) near $\lambda$ 3900; (I, o) near $\lambda_{3650}$; (I, I) near $\lambda$ 4040; and the similar transitions for $C D$.

The $(\mathrm{I}, \mathrm{O})$ band is certainly absent, and the (I, I) band falls in the region of $\lambda 4050$. Some lines coincide with observed features; but, assuming a plausible error in wave length, there is no regularity whatsoever of the "low-temperature type" observed for the $(0,0)$ bands of $\mathrm{B}^{2} \Sigma^{-} \rightarrow \mathrm{x}^{2} \Pi$ and $\mathrm{A}^{2} \Delta \rightarrow \mathrm{x}^{2} \Pi$. The absence of the (I, I) band may thus be considered as certain. The identifications of lines of the $(0,0)$ transition are collected in Table 9. They are shown in Plate XVI and in the tracings of Figure 7. The $R$ branch is weaker than the $P$ and $Q$ branches. It would fall into the strong $C N$ pattern, and it is not observed there because all the observed lines extend over the entire head, whereas the $\mathrm{CH}$ lines are always very short.

All the lines observed between $\lambda_{3886}$ and $\lambda_{3922}$ are concentrated very close to the nucleus, and there is no trace of a line besides the ones listed in Table 9. The agreement

${ }^{48}$ C.R., 206, I550, г938; $A$ p. J., 91, 91, I940.

${ }_{49}$ Arkiv för matematik, astronomi och fysik, 27, No. I9, I94I. 
with the laboratory data is excellent. For example, there is no unidentified cometary line around $\lambda$ 39I9, as Dufay had reported, and $N_{2}^{+}$is absent. This may be a characteristic feature of Comet Cunningham. Nevertheless, the complexity of the solar spectrum in

TABLE 10

$(\circ, 0)$ BAND OF $\mathrm{A}^{2} \Delta \rightarrow \mathrm{x}^{2} I \mathrm{OF} C H$

\begin{tabular}{|c|c|c|c|c|}
\hline \multicolumn{2}{|c|}{ Comet } & \multicolumn{3}{|c|}{ LABORATORY } \\
\hline$\lambda$ & Int. & $\lambda$ & Branch & $K$ \\
\hline $428 I$ & $0-1$ & $\begin{array}{l}4280 . I \\
4279.6\end{array}$ & $\begin{array}{l}R_{\mathrm{I}} \\
R_{2}\end{array}$ & $\begin{array}{l}5 \\
5\end{array}$ \\
\hline $4285 \cdot 7$ & $I-O$ & $\begin{array}{l}4286.2 \\
4285 \cdot 5\end{array}$ & $\begin{array}{l}R_{\mathrm{I}} \\
R_{2}\end{array}$ & $\begin{array}{l}4 \\
4\end{array}$ \\
\hline $429 I .7$ & $I-2$ & $\begin{array}{l}4292 . I \\
429 I .2\end{array}$ & $\begin{array}{l}R_{1} \\
R_{2}\end{array}$ & $\begin{array}{l}3 \\
3\end{array}$ \\
\hline $4297 \cdot 3$ & $3 n^{*}$ & $\begin{array}{l}4298.0 \\
4296.6\end{array}$ & $\begin{array}{l}R_{1} \\
R_{2}\end{array}$ & $\begin{array}{l}2 \\
2\end{array}$ \\
\hline 4300.2 & $2-3 s$ & $4300 \cdot 3$ & $R_{2}$ & I \\
\hline $4303 \cdot 9$ & $4 \mathrm{~S}$ & $4303 \cdot 9$ & $R_{\mathrm{I}}$ & I \\
\hline $4313 \cdot 2$ & $6 n \dagger$ & $\begin{array}{l}43 \mathrm{I} 4.2 \\
43 \mathrm{I} 3.6 \\
43 \mathrm{II} 2.7 \\
43 \mathrm{I} 3.0 \\
43 \mathrm{I} 2.2 \\
43 \mathrm{II} 2.2 \\
43 \mathrm{II} .6 \\
43 \mathrm{II} \cdot 3\end{array}$ & $\begin{array}{l}Q_{\mathrm{I}} \\
Q_{\mathrm{I}} \\
Q_{2} \\
Q_{\mathrm{I}} \\
Q_{2} \\
Q_{\mathrm{I}} \\
Q_{2} \\
Q_{\mathrm{I}}\end{array}$ & $\begin{array}{l}2 \\
3 \\
3 \\
4 \\
4 \\
5 \\
5 \\
6\end{array}$ \\
\hline $4329 \cdot 3$ & $I-2$ & $\begin{array}{l}4330.0 \\
4328.9\end{array}$ & $\begin{array}{l}P_{\mathrm{I}} \\
P_{2}\end{array}$ & $\begin{array}{l}3 \\
3\end{array}$ \\
\hline 4334.2 & $I-2$ & $\begin{array}{l}4334.8 \\
4333 \cdot 9\end{array}$ & $\begin{array}{l}P_{\mathrm{I}} \\
P_{2}\end{array}$ & $\begin{array}{l}4 \\
4\end{array}$ \\
\hline 4339.0 & $I-O$ & $\begin{array}{l}4339 \cdot 3 \\
4338.7\end{array}$ & $\begin{array}{l}P_{1} \\
\mathrm{P}_{2}\end{array}$ & $\begin{array}{l}5 \\
5\end{array}$ \\
\hline 4344 & $0-1$ & $\begin{array}{l}4343.8 \\
4343 \cdot 4\end{array}$ & $\begin{array}{l}P_{\mathrm{I}} \\
P_{2}\end{array}$ & $\begin{array}{l}6 \\
6\end{array}$ \\
\hline 4348 & O-I & $\begin{array}{l}4348.2 \\
4347.7\end{array}$ & $\begin{array}{l}P_{\mathrm{I}} \\
P_{2}\end{array}$ & $\begin{array}{l}7 \\
7\end{array}$ \\
\hline
\end{tabular}

* This line is not so sharp as the following one, $\lambda 4300$.

$\dagger$ Extending from $\lambda 43$ Ir to $\lambda_{43}$ I 5 .

the violet region renders cometary identifications difficult, especially on slitless spectrograms of the type used by Dufay. No evidence is found on our spectrograms of anything besides the $C H$ lines. The bands of $\mathrm{CO}^{+}, C N$ (tail band Io $\rightarrow$ Io), and others which fall in the same region are absent. 
System $\mathrm{A}^{2} \Delta \rightarrow \mathrm{x}^{2} \Pi$.-Laboratory data are available for the $(\mathrm{O}, \mathrm{O})$ and $(\mathrm{I}, \mathrm{I})$ bands of $C H$ and $C D$. The $(\circ, 0)$ band falls in the region of the solar $\mathrm{G}$ band; and the complexity of the Fraunhofer spectrum, especially between $\lambda$ 43I 5 and $\lambda 435^{\circ}$, complicates the identification of the fainter components of the band and also the estimated intensities. For

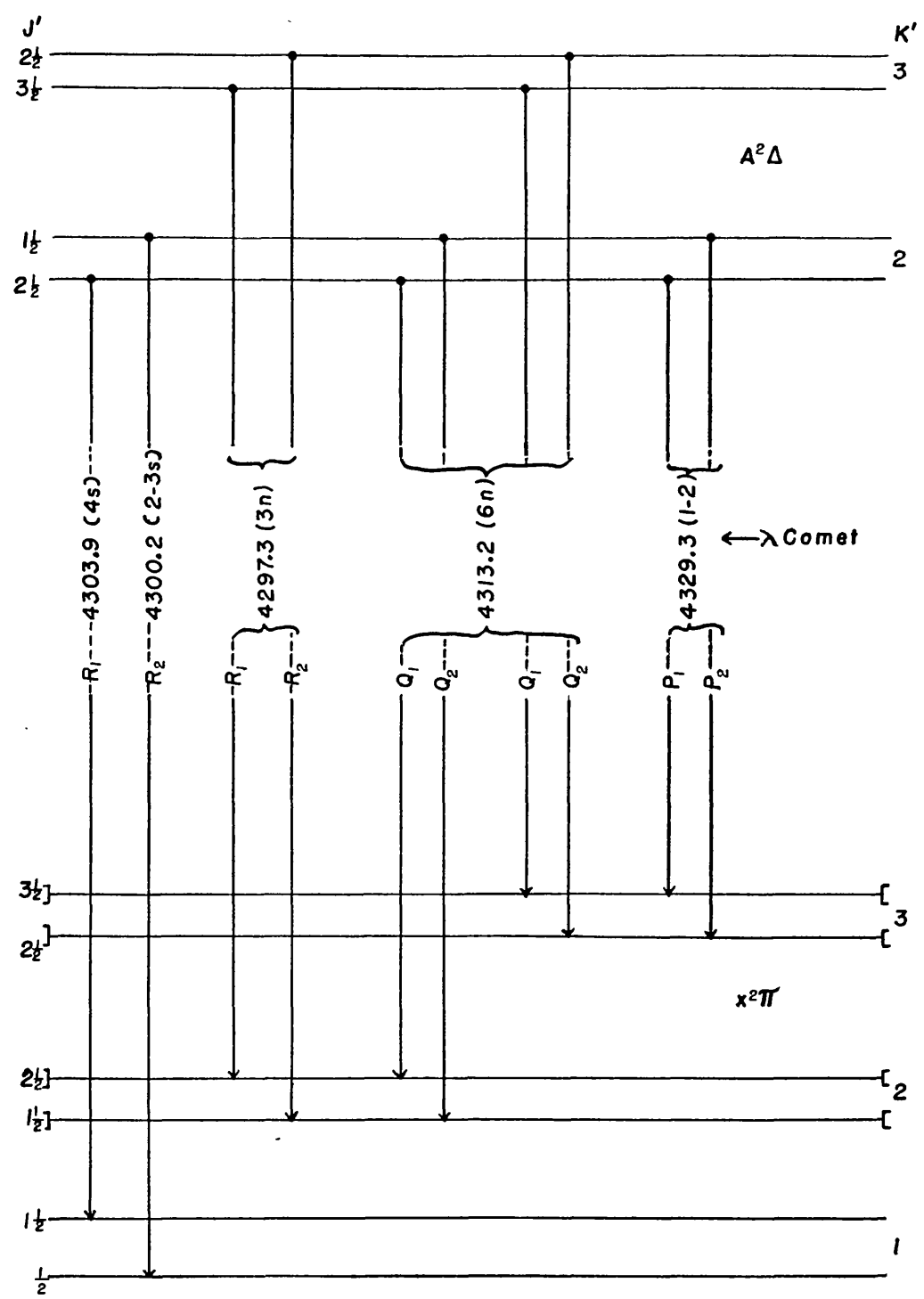

Fig. 8.-Level diagram of the strongest $\mathrm{CH}$ lines observed in Comet Cunningham. Emissions are registered downward.

example, the Fraunhofer structure has a tendency to make the $P$ lines seem unusually strong by contrast owing to absorption lines on either side. But after consideration of the solar effect, the $P$ branch, although certainly present, turns out to be weak compared to the $R$ branch, which is what we should expect theoretically and experimentally.

The identifications are summarized in Table Io, and the strongest lines are shown schematically in Figure 8. The $K$ values in the fifth column of Table ro correspond to the 
$J^{\prime \prime}$ values in the following way:

$$
\begin{aligned}
& J^{\prime \prime}=K+\frac{1}{2} \text { for } P_{\mathrm{I}}, Q_{\mathrm{I}}, R_{\mathrm{I}} \\
& J^{\prime \prime}=K-\frac{1}{2} \text { for } P_{2}, Q_{2}, R_{2} .
\end{aligned}
$$

The relative theoretical intensities of the first lines are approximately

$$
P_{\mathrm{I}}: P_{2}=20: \mathrm{I} 4 ; \quad Q_{\mathrm{I}}: Q_{2}=98: 63 ; \quad R_{\mathrm{I}}: R_{2}=\mathrm{I} 89: 105,
$$

or

$$
P_{\mathrm{I}}>P_{2} ; \quad Q_{\mathrm{I}}>Q_{2} ; \quad R_{\mathrm{I}}>R_{2} ; \quad R>Q>P .
$$

In the fourth column the branches have the following meaning:

$$
\begin{aligned}
& R_{\mathrm{I}}=R_{\mathrm{I} c d}+R_{\mathrm{I} d c} \\
& R_{2}=R_{2 c d}+R_{2 d c}
\end{aligned}
$$

and similarly for $P_{\mathrm{I}}, P_{2}, Q_{\mathrm{I}}$, and $Q_{2}$; in the present case the satellite branches have no importance.

We find no trace in Comet Cunningham of the line $\lambda$ 43I 8.4 observed by Dufay and attributed tentatively by him to the Vegard-Kaplan band I $\rightarrow$ I 3 of $N_{2}$. There is no trace either of the unidentified line $\lambda 4325.5$ reported by Dufay. In Comet Cunningham all the emissions observed between $\lambda 4280$ and $\lambda 435^{\circ}$ are unambiguously identified with the $(0,0)$ transition of $\mathrm{A}^{2} \Delta \rightarrow \mathrm{x}^{2} \Pi$ of $C H$. Especially, there is no trace of a line between $\lambda 4304$ and $\lambda$ 43I I which might have been attributed to the strongest lines of the ${ }^{2} \Delta \rightarrow{ }^{2} \Pi$ $(\circ, 0)$ transition of carbon deuteride. Accordingly, our material does not reveal any appreciable amount of deuterium, but this search should be repeated using a higher resolving-power.

The (I, I) band, according to Fagerholm's analysis, coincides almost with the (o, o) band; the strongest expected lines would be

$$
\begin{aligned}
& \text { Branches } R_{\mathrm{I}}-R_{2}: \lambda 4303 . \mathrm{I} \text { and } \lambda \text { 4301.I; } \\
& \text { Branches } Q_{\mathrm{I}}-Q_{2}: \lambda_{43} \text { I3.0 and } \lambda \text { 43 I I.5. }
\end{aligned}
$$

It is obvious that these lines, if present, would be hopelessly blended in the much stronger $(0,0)$ band.

Examination of Plate XVI and Figure 9, especially a comparison of the spectrograms of December I $7(r=0.85)$ and December 31 $(r=0.57)$, I940, shows that, despite the rather small variation of $r$, the intensity ratios in the $R$ branch have changed appreciably, favoring a higher $J$ for a smaller distance $r$.

\section{BANDS OF $C_{2}$}

The relative intensities among the strong Swan bands of $C_{2}$ are very similar to the laboratory distribution at $T \simeq 3000^{\circ}$. As was shown by $\mathrm{K}$. Wurm, this behavior is related to the absence of a permanent electric dipole moment.

The Swan bands are the only transitions of $C_{2}$ in the observable region involving the ground electronic level $A^{3} \Pi$. A series of bands, often called the "high-pressure bands" or "Fowler's bands," was attributed until recently to another electronic transition involving the ground level $A^{3} \Pi$. But G. Herzberg ${ }^{50}$ has shown that they are simply Swan bands

${ }^{50} \mathrm{Op}$. cit. 
with $v^{\prime}=6$. The selective excitation of the one vibrational level $v^{\prime}=6$ would be due, according to Herzberg, to the fact that $C_{2}$ molecules in this state are formed by the recombination of two $C$ atoms in a three-body collision, the heat of dissociation of $C_{2}$ being transformed into energy of excitation of $C_{2}$. Such a process is hardly to be expected in a cometary head. A fairly strong band was measured on our spectrograms at $\lambda 5_{5228.3}$ (int. 4) and was also observed by R. Minkowski ${ }^{5}$ in the spectrum of Comet Finsler (I937f); Minkowski attributed that feature to one of Fowler's bands, with head at $\lambda$ 5434.9. This identification is probably not real.

With regard to the Swan bands, our spectrograms show the usually well-developed sequences ${ }^{2} \Delta v=-2,-\mathrm{I}, 0,+\mathrm{I},+2$. In the sequence $\Delta v=-2$ which was represented by only one band in Bobrovnikoff's work on Halley's Comet, our strongest exposures show six successive bands, up to $(5 \cdot 7)$ at $\lambda 5923$.

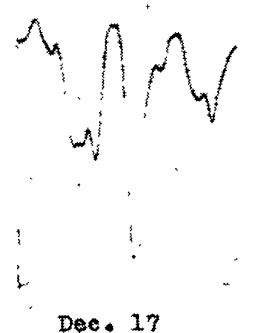

Dee. 17

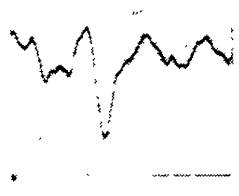

Dec. 25

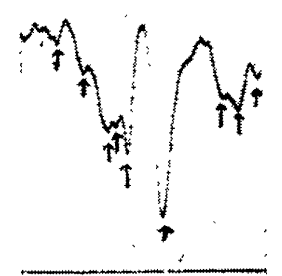

Dec. 23

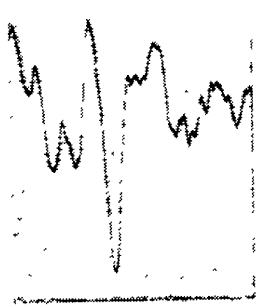

Dec. 27
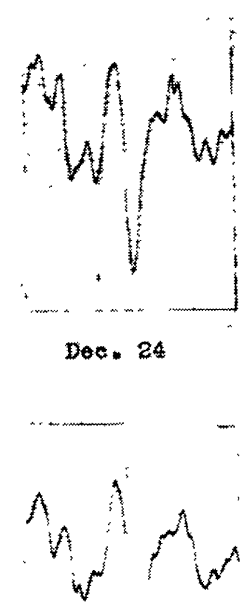

Dec. 31

FIG. 9.-Microphotometer tracings of the $\mathrm{A}^{2} \Delta \rightarrow \mathrm{x}^{2} \Pi$ band of $\mathrm{CH}$ on December $17,23,24,25,27$, and $3 \mathrm{I}, \mathrm{I}$ 940. Emissions are registered downward.

In the $\Delta v=-$ I sequence the first four bands are very strong (successive intensities 9 , Io, 8, 6); and the fifth, at $\lambda 5473(4,5)$, is extremely weak. Then come again two fairly strong bands, with maxima at $\lambda_{5445}$ (int. 4) and $\lambda 5_{52} 8$ (int. 4). Minkowski has tentatively attributed them to $C O$ (Asundi system) and to $C_{2}$ (Fowler's series), respectively. These identifications are very uncertain. P. C. Keenan ${ }^{53}$ has made a search for these bands in carbon stars where the first four bands are strong and the fifth absent; he finds that $\lambda_{5445}$ and $\lambda_{5428}$ are absent.

$\mathrm{K}$. Wurm ${ }^{54}$ has determined the convergences of the $\Delta v=0$ and $+\mathrm{I}$ sequences. These are at $\lambda_{498}$ and $\lambda_{4} 6_{52}$, and they probably explain the broad bands at $\lambda{ }_{497} 6$ and $\lambda_{4642}$ observed by Sanford ${ }^{55}$ and Shane ${ }^{56}$ in the late $N$ stars, which are degraded toward the red. There is no definitive evidence for the presence of any of these convergences in

${ }^{51}$ Pub. A.S.P., 49, 276, I937.

${ }^{52}$ Old designations, respectively: $C \mathrm{I}, C \mathrm{II}, C \mathrm{\amalg I}, C \mathrm{rv}, C \mathrm{v}$.

53 Private communication.

${ }^{55}$ Pub. A.S.P., 38, 177, 1926.

${ }_{54} Z s . f . A p .$, i3, i 79, I936.

${ }^{56}$ Lick Obs. Bull., 13, 123, 1928. 
Comet Cunningham; this absence may be due to the fact that the "temperature" of the $C_{2}$ bands, which is around $3000^{\circ} \mathrm{K}$, is too high, so that the first members of low vibrational numbers extend too far to the violet and thus smear out the convergence regions.

Among the other unidentified bands observed by Shane and Sanford, the two strongest are: $\lambda 4540$ (stellar int. 6) and $\lambda{ }_{4867}$ (stellar int. 8); we measured two cometary bands at $\lambda$ 454I (int. In) and $\lambda 4868$ (int. I), which are probably due to the same unidentified system.

Our material does not provide any evidence for the presence of the $C_{\mathrm{r}_{3}}$ isotope.

\section{THE " $\lambda 4050$ GROUP"}

As has been the case in practically all comets, Comet Cunningham reveals a group of strong, "nuclear" lines in the region $\lambda \lambda 3980-4 I 30$; these lines do not appear like degraded bands; they extend in the head to larger distances than $\mathrm{CH}$ (see Pl. XVII). A thorough discussion of these bands based upon the material available to I93 I, together with a bibliography, was published by Bobrovnikoff. ${ }^{57}$ It seems at present rather inadequate to use the expression "Raffety bands" for the cometary radiations, and we suggest replacing it by the expression " $\lambda$ 4050 group" as long as the emitting molecules are not identified.

Several molecules appearing, or likely to appear, in comets give bands in this region, among which we shall consider:

a) Carbon: $C_{2}$ (Deslandres-D'Azambuja system $\mathrm{x} \Pi \rightarrow \mathrm{x} \Pi$ )

b) Cyanogen: $C N$ (tail bands or new system suggested by Bobrovnikoff)

c) Hydrocarbon: $C H\left([\mathrm{r}, \mathrm{r}]\right.$ band of the $2 \Sigma^{-} \rightarrow{ }^{2} \Pi$ system or a new system as suggested by J. Cabannes and J. Dufay)

d) Sodium hydride: $N a H$

The Deslandres-D'Azambuja system of $C_{2}$ has been analyzed by Dieke-Holtgreven ${ }^{8}$ and by Kopfermann and Schweitzer. ${ }^{59}$ Each band consists of two $P, Q$, and $R$ branches in which every second line is missing. The $v^{\prime}-v^{\prime \prime}=0$ sequence should be strongest, especially $(0,0)$ at $\lambda 3_{5} 8^{2}$, but this is absent in comets. The $v^{\prime}-v^{\prime \prime}=-$ I sequence appears in the region of $\lambda$ 4roo; but there is no plausible identification in comets on the basis of the rotational analysis.

The tail bands of $C N$ are not present, as was shown in section 3. Bobrovnikoff's suggestion $^{60}$ to attribute part of the $\lambda 405^{\circ}$ group to a new system of $C N$ is also unlikely, since the $\lambda 4050$ group is nuclear, which is contrary to $C N 3880$ and which is not in harmony with the fact that the laboratory investigation of the $C N$ spectrum is satisfactory.

The (I, I) band of the ${ }^{2} \Sigma^{-} \rightarrow{ }^{2} \Pi$ system of $C H$, which was observed by Raffety, has been investigated with high dispersion by $\mathrm{H}$. Grenat ${ }^{6 \mathrm{r}}$ and later by E. Fagerholm. ${ }^{62}$ As the $(0,0)$ band of the same system is very weak in comets and as the "low-temperaure, lines" of the (I, I) band do not give satisfactory agreement with the observed features, it appears safe to exclude this possibility of identification of the "Raffety band." This is in agreement with F. Baldet. ${ }^{6} 3$ J. Cabannes and J. Dufay ${ }^{64}$ have noticed that certain characteristic regularities appear to connect some of the radiations of the $\lambda 4050$ group and the $C H$ lines near $\lambda$ 43 I3; especially striking was a nearly constant wave-number difference of about ${ }_{1} 500 \mathrm{~cm}^{-1}$ connecting ten pairs of lines of the $\lambda 4050$ group and of the $\mathrm{CH}$ band near $\lambda{ }_{43}{ }^{1} 3 .{ }^{65}$ Our observations confirm this approximately constant difference
${ }^{57}$ Ap. J., 73, 6I, I931.
${ }^{59}$ Zs.f. Phys., 6r, 87, г930.
${ }^{8}$ Zs.f. Phys., 62, 767, I930.
${ }^{60} A$ p. J., 73, 6r, r93 $\mathrm{r}$.
${ }^{6 x}$ C.R., I92, I553, I93 I; Grenat used an oxyacetylene blow-pipe flame.
${ }^{62} \mathrm{Op}$. cit.; Fagerholm used a carbon arc burning in an atmosphere of hydrogen.
${ }^{63}$ C.R., 192, I $53 \mathrm{I}, \mathrm{I} 93 \mathrm{I}$.
${ }^{64}$ C.R., 203, 903, 1936; 206, I550, 1938.
${ }_{6}$ C.R., 206, I550, 1938, Table 2. 
only in the case of five pairs. Of course, such a coincidence, as was pointed out by Dufay, may be purely accidental. As no laboratory investigation confirms the proposed new $\mathrm{CH}$ system, it seems rather probable that the $\lambda 4050$ group is not related to $C H$. On the basis of intensity variations Bobrovnikoff had already noticed that the association of the $\lambda 4050$ group with the $C H$ bands could not be close. This is confirmed in the case of Comet Cunningham. As.was also noticed by the Victoria observers, ${ }^{66}$ the $\lambda 4050$ group decreased steadily in intensity compared to $C N$, whereas the $C H$ band increased in intensity; our spectrograms of October 22, November 14, and November 30, 1940, show the $\lambda 405 \circ$ group to be very strong and $C H$ very weak, whereas in the beginning of January, I94I, $C H \lambda 43$ I 3 was stronger than any line of the $\lambda 4050$ group. This group has not exactly the same extension in the head as the $C H$ molecules.

The $v^{\prime \prime}=0$ and $v^{\prime \prime}=\mathrm{I}$ series of $N a H$ appear in the violet and blue regions, but the "low-temperature lines" do not provide a satisfactory identification.

A systematic discussion of other possible molecules, such as $\mathrm{SiH}, \mathrm{AlH}$, etc., did not reveal any known molecular spectrum which could be responsible for the $\lambda 4050$ group. A search by P. C. Keenan ${ }^{67}$ failed to reveal the group of lines in carbon stars. Considering our present satisfactory knowledge of the band spectra of neutral diatomic molecules, it seems plausible to attribute tentatively the $\lambda 405$ o group either to some forbidden transition or to some ionized molecule. Among the ionized light diatomic molecules, we have good laboratory data only for $\mathrm{CO}^{+}, \mathrm{N}_{2}^{+}$and $\mathrm{O}_{2}^{+}$; a small amount of information, but quite insufficient, is available for $\mathrm{OH}^{+}$, but, as far as we know, there is nothing known about $\mathrm{CH}^{+}, \mathrm{CN}^{+}, \mathrm{C}_{2}^{+}, \mathrm{NH}^{+}$, and $\mathrm{NO}^{+}$. Contrary to $\mathrm{CO}^{+}$and $\mathrm{N}_{2}^{+}$, which extend far in the tail, the hypothetical ionized molecule would not extend far from the nucleus, which simply means that it would be photodissociated much more easily than $\mathrm{CO}^{+}$and $\mathrm{N}_{2}^{+}$. Evidently, we cannot yet exclude the possibility of a still uninvestigated polyatomic molecule.

Our measured wave lengths in the region $\lambda \lambda$ 3950-4I40 are collected in Table II, together with the wave lengths by Bobrovnikoff and by Baldet. The probable error of our wave lengths is about $\pm 0.3 \mathrm{~A}$ for the lines of intensity 2 or higher; it may increase to \pm 0.5 A for weaker lines.

\section{VARIOUS PROBLEMS}

Visual region.-No trace of Balmer absorption has been observed on our spectrograms, contrary to observations reported from the Harvard Observatory; ${ }^{68}$ a slit spectrogram taken on December ro (the same night as the Harvard observation) fails to reveal any appreciable Balmer absorption.

On January 3, I94I, our spectrogram (see Pl. XVII) revealed a nuclear feature whose measured wave length was $\lambda 5^{895}$ and which we attributed ${ }^{69}$ to a cometary $N a$ emission. On the following nights the possible nuclear line became masked by the long twilight line of $N a$, and the position of the comet prevented us from securing additional material. The D line was not observed on a spectrogram taken at the Dominion Astrophysical Observatory on January $5,,^{70}$ whereas a line was recorded at $\lambda 6302$ in the region also covered by our spectrograms; the twilight line does not seem to have been recorded on the Victoria spectrogram. It does not appear probable that the nuclear feature which we observed on January 3 may have been an accidental defect of the film. Actually, the line measured at $\lambda 5^{895}$ was weaker than the feature at $\lambda 6302$ (the intensities on our scale were 3 and 5). Incidentally, it should be noted that the behavior of the $N a$ emission has sometimes been observed to be irregular (e.g., in Halley's Comet).

\footnotetext{
${ }^{66}$ Harvard Ann. Card, No. 562, I941.

${ }^{67}$ Private communication.

${ }^{69}$ Ibid., No. 556, 194I.

${ }^{68}$ Harvard Ann. Card, No. 55I, 1940.

${ }^{70}$ Ibid., No. $5^{62}$, I941.
} 
In the region covered by our material $(\lambda<64 \mathrm{I} 4)$ all the features observed by R. Minkowski in Comet Finsler are confirmed.

Various molecules.- The bands of the two characteristic molecules of a comet tail, $\mathrm{CO}^{+}$and $\mathrm{N}_{2}^{+}$, have sometimes been observed in comet heads, and it is well known since

TABLE 11

$\lambda 4050$ GROUP (REGION $\lambda \lambda$ 3950-4I40)

\begin{tabular}{|c|c|c|c|c|c|}
\hline \multicolumn{3}{|c|}{ Comet Cunningham } & \multicolumn{2}{|c|}{ Other Comets } & \multirow{2}{*}{ Notes } \\
\hline$\lambda$ & Int. & $\begin{array}{l}\text { No. of } \\
\text { Plates }\end{array}$ & $\lambda$ (Bobr.) & $\lambda$ (Baldet) & \\
\hline 3950.2 & $2 \mathrm{n} ?$ & 6 & $\ldots \ldots$ & 3950 & \\
\hline 3954.0 & I & 2 & $\ldots \ldots \ldots$ & $\ldots \ldots \ldots$ & \\
\hline 3960.2 & $I-2$ & 5 & $\ldots \ldots \ldots$ & $\ldots \ldots \ldots$ & \\
\hline $3963 \cdot 5$ & $I-2$ & 5 & $\ldots \ldots \ldots$ & 3962.5 & \\
\hline$\ldots \ldots$ & $\cdots$ & & $\ldots \ldots$ & $3968.4(2)$ & \\
\hline 3972.7 & 2 & 7 & $\ldots \ldots \ldots$ & 3974.8 & \\
\hline 3979.7 & $I-2$ & 4 & $\ldots \ldots \ldots$ & 3982.4 & \\
\hline 3987.2 & 3 & 8 & 3987.0 & $3988.4(3)$ & \\
\hline 3992.6 & $4 \mathrm{n}$ & 8 & $3993 \cdot 3$ & $3993 \cdot \mathrm{I}(4)$ & I \\
\hline $3997 \cdot 5$ & $I-O$ & 3 & $\ldots \ldots$ & $\ldots \ldots \ldots$ & \\
\hline 4002.2 & 2 & 8 & 4002.9 & $4002.0(4)$ & \\
\hline $4007 \cdot 5$ & I & 6 & $\ldots \ldots \ldots$ & $\ldots \ldots \ldots \ldots$ & \\
\hline 4013.2 & 4 & 8 & $4014 \cdot 3$ & $4014 \cdot 5](8)$ & \\
\hline $4019 \cdot 4$ & $4 \mathrm{n}$ & 8 & 4020.0 & $4020.1 \int^{(0)}$ & \\
\hline $4024 \cdot 3$ & $I-O$ & 2 & $\ldots \ldots$ & 4025 & \\
\hline 4027.6 & $I-O$ & 3 & $\ldots \ldots \ldots$ & $\ldots \ldots \ldots \ldots$ & \\
\hline 4033.2 & 2 & 7 & $403 I \cdot 5$ & $4032.6(3)$ & 2 \\
\hline 4039.6 & 5 & 8 & $4039 \cdot 3$ & 4039.6 (9) & 3 \\
\hline 4043.6 & 5 & 8 & 4042.4 & $4043.0(9)$ & 3 \\
\hline 4051.6 & 6 & 8 & $405^{2} . I$ & 4051.6 (10) & \\
\hline 4054.2 & $I-2$ & 5 & $\ldots \ldots \ldots$ & $4054 \cdot 5$ & \\
\hline $4064 \cdot 3$ & $I-2$ & 6 & $\ldots \ldots \ldots$ & $4065 \cdot 3$ & \\
\hline 4068.4 & $2-3$ & 8 & 4067.2 & $4067.7(7)$ & 4 \\
\hline 4074.4 & 4 & 8 & 4074.2 & 4074.0 (9) & \\
\hline 4084.8 & $I-O$ & 4 & 4085.8 & $4085.1(2)$ & \\
\hline 4090.0 & $I-0$ & 5 & $\ldots \ldots \ldots$ & 4089 & \\
\hline $4099 \cdot 5$ & 2 & 7 & 4099.6 & $4099.6(3)$ & \\
\hline $4109 \cdot 4$ & $I-O$ & 5 & 4109.I & $4 \operatorname{IOg} \cdot 3(3)$ & \\
\hline $4 I 24 \cdot 4$ & I-on & 6 & $\ldots \ldots \ldots$ & $4 \mathrm{I} 24.6$ (I) & 5 \\
\hline $4 I 37.8$ & $0-I$ & 4 & & $4 \mathrm{I} 37 \cdot 5$ & \\
\hline
\end{tabular}

NOTES TO TABLE 11

r. Possibly double.

2. Possibly double.

3. A line is possibly present between $\lambda 4039.6$ and $\lambda 4043.6$, at $\lambda$ 404r.8 (4).

4. Possibly double at $\lambda \lambda 4066.7$ (2)-4069.8 (3).

5 . Broad feature with several maxima.

Baldet's investigations ${ }^{7 \mathrm{r}}$ that the $\mathrm{CO}^{+}$and $\mathrm{N}_{2}^{+}$molecules do exist in the head; but these bands were absent on our spectrograms.

There is no evidence of the Lyman-Birge-Hopfield system of $\mathrm{N}_{2}$; the presence of this system in the night-sky spectrum has been tentatively suggested..$^{22}$ The evidence for the

${ }^{7 x}$ Ann. Obs. Astr. Phys., 7, Paris, 1926.

${ }^{72}$ Ap. J., 93, 337, 1941. 
Vegard-Kaplan and the other systems of $N_{2}$ is, on the basis of our spectrograms, extremely meager; this applies also to the $\beta$ bands of $N O$. The probable presence of $N_{2}$ and $N O$ in the head has been announced by Dufay, ${ }^{73}$ mostly on the basis of microphotometer tracings of objective-prism spectrograms. This is an important question which should be rediscussed on the basis of slit spectrograms of adequate dispersion.

The $C O$ molecule has been extensively investigated in many laboratories; it has no resonance system in the observable region. Minkowski has suggested that the Asundi system $\mathrm{a}^{\prime} 3 \Sigma \rightarrow \mathrm{a}^{3} \Pi$ (exc. pot. of $3 \Sigma=7 . \mathrm{I} 3 \mathrm{v}$.) may have been present in Comet Finsler; but this should be confirmed on the basis of better observational material in the red and infrared regions. We have considered the other observable systems: the third positive $\left(b^{3} \Sigma \rightarrow a^{3} \Pi\right)$, the triplet bands $\left(d^{3} \Pi \rightarrow a^{3} \Pi\right)$, Herzberg's bands $\left(c^{1} \Sigma \rightarrow A^{1} \Pi\right)$, and the Angström system $\left(\mathrm{B}^{\mathrm{I}} \Sigma \rightarrow \mathrm{A}^{\mathrm{I}} \Pi\right)$. In no case is there any conclusive evidence, so that the presence of nonresonance systems of $C O$ should still be considered as hypothetical.

For the physics of comets it appears that at present the greatest need is for observations in the red and infrared regions with sufficient dispersion (say about $100 \mathrm{~A} / \mathrm{mm}$ ). Several molecules - diatomic as well as polyatomic - could be detected there, and several still unsettled problems may be solved. It is probable also that the resonance lines of potassium ( $\lambda$ 7664.9 and $\lambda$ 7699.0) would be observed at small solar distances because the boiling-point of $K$ is only $762^{\circ} \mathrm{C}$ (against $877^{\circ} \mathrm{C}$ for $N a$ ) and because it is a cosmically abundant element.

Our thanks are due to Dr. O. Struve and Dr. H. Beutler for helpful advice.

McDonald ObSeRvatory

May I94I

${ }^{73} C . R .$, 204, 744, 1937. 
PLATE XIVb

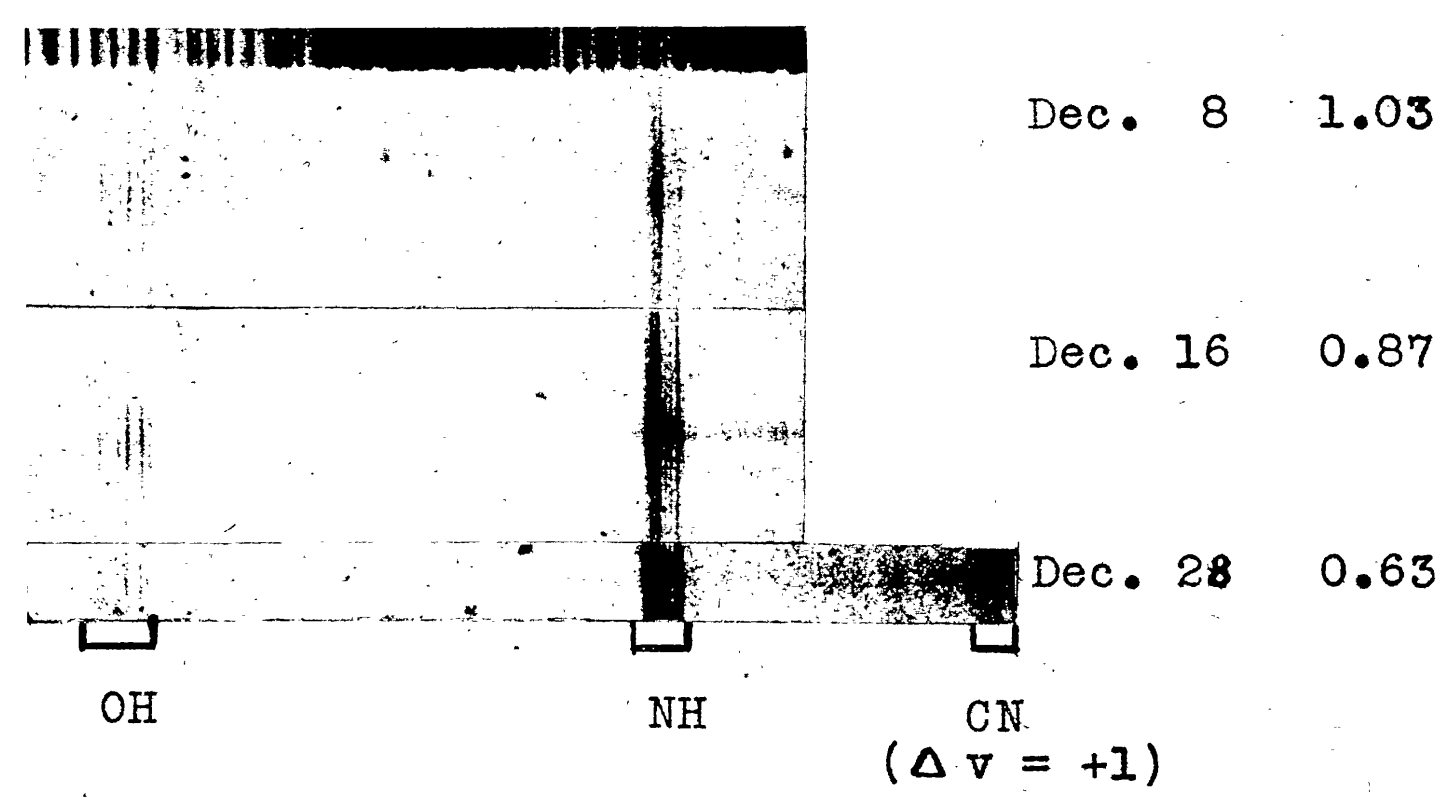

The Ultraviolet Region of the Spectrum of Comet Cunningham on DeCEMBer 8, i6, AND 28, I940

The heliocentric distances are given on the right 


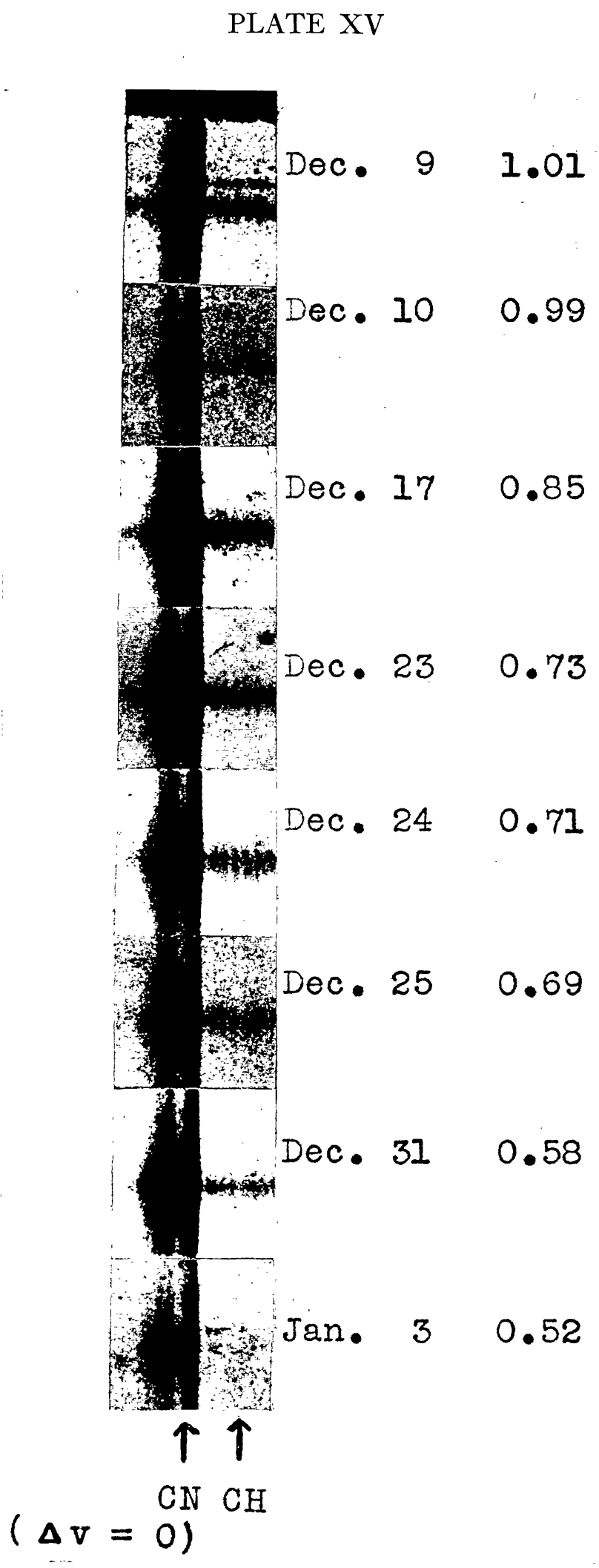

The $\Delta v=$ o SEQUence of $C N$ AND THE $\mathrm{B}^{2} \Sigma^{-} \rightarrow \mathrm{x}^{2} \Pi$ BAND OF $C H$ DUR-

ing the Period December 9, i940, to January 3, i94I

Spectrograms obtained with the glass spectrograph of the McDonald Observatory 


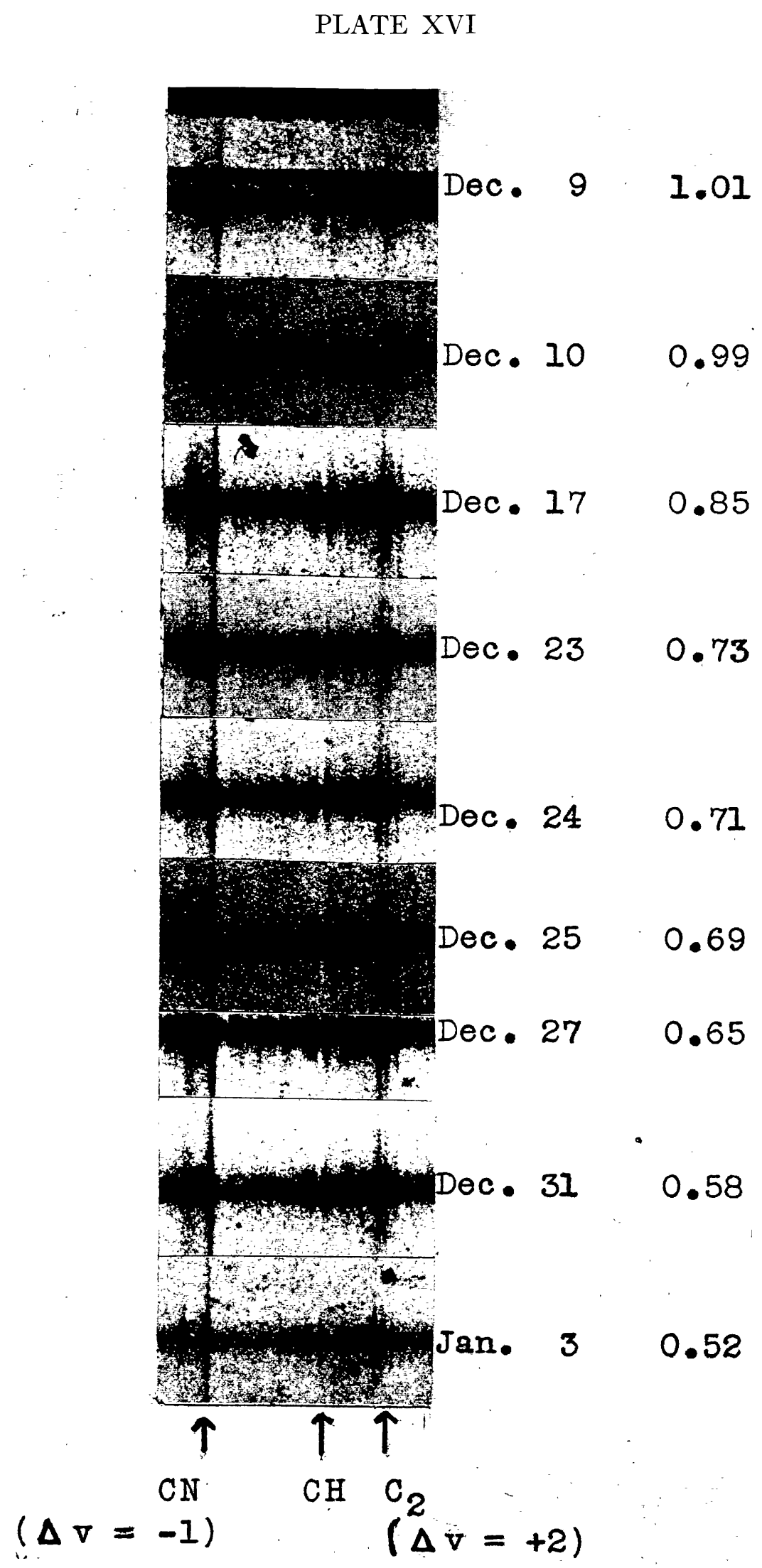

The Region $\lambda \lambda$ 4I 50-4400 DUring the Period December 9, i940, to January 3, i94I 


\section{PLATE XVII}

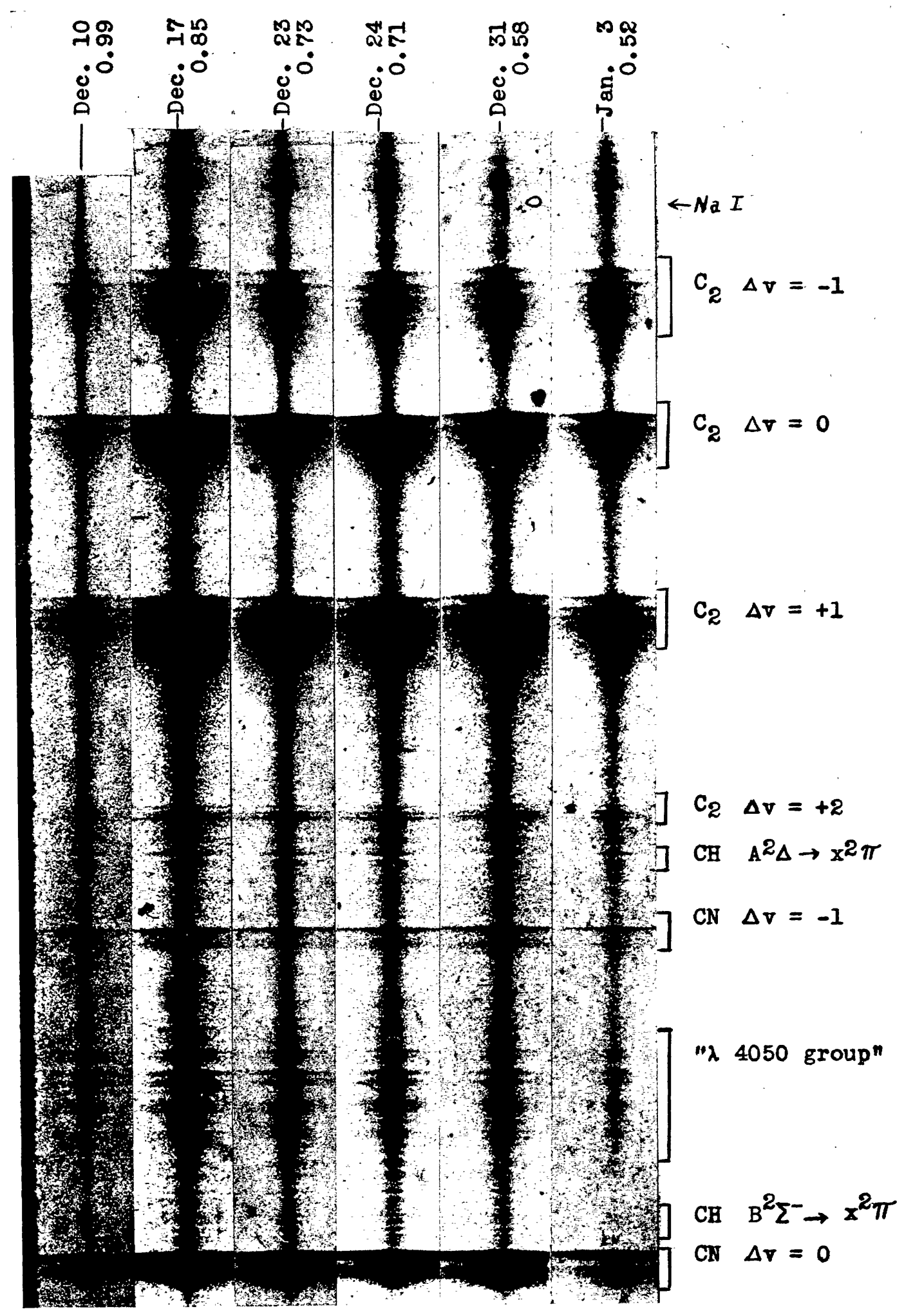

The Region $\lambda \lambda$ 3850-6250 during the Period December io, i940, to January 3, i94I 